Check for updates

Cite this: RSC Adv., 2019, 9, 33693

Received 17th September 2019 Accepted 14th October 2019

DOI: $10.1039 / \mathrm{c} 9 \mathrm{ra07509g}$

rsc.li/rsc-advances

\section{Strategic tuning of excited-state properties of electroluminescent materials with enhanced hot exciton mixing $\dagger$}

\author{
Jayaraman Jayabharathi, (D) * Venugopal Thanikachalam, (D) Ramaiyan Ramya \\ and Sekar Panimozhi
}

\begin{abstract}
Deep blue emitters with excellent stability, high quantum yield and multifunctionality are the major issues for full-color displays. In line with this, new multifunctional, thermally stable blue emitters viz., $N$-(4-(10-(1(2,3-dihydrobenzo[b] [1,4]dioxin-6-yl)-1H-phenanthro[9,10- $d$ ] imidazol-2-yl)anthracen-9-yl)phenyl)- $N$ phenylbenzenamine (DPIAPPB) and 2-(10-(9H-carbazol-9-yl)anthracen-9-yl)-1-(2,3-dihydrobenzo[b] [1,4] dioxin-6-yl)-1H-phenanthro[9,10-d]imidazole (CADPPI) with hybridized local charge transfer state (HLCT) and hot exciton properties have been synthesized. These molecules show high photoluminescence quantum yield $\left(\Phi_{\mathrm{s} / \mathrm{f}}\right)$ : (DPIAPPB $-0.82 / 0.70$ and CADPPI $-0.91 / 0.83$ ). The CADPPI based device (EL $-467 \mathrm{~nm}$ ) shows high efficiencies $\left[\eta_{\mathrm{c}}-9.85 \mathrm{~cd} \mathrm{~A}^{-1} ; \eta_{\mathrm{p}}-10.84 \mathrm{~lm} \mathrm{~W}^{-1} ; \eta_{\mathrm{ex}}-4.78 \%\right.$ at $2.8 \mathrm{~V} ; \mathrm{CIE}(0.15,0.10)]$ compared to the DPIAPPB device (EL $-472 \mathrm{~nm})\left[\eta_{\mathrm{c}}-6.56 \mathrm{~cd} \mathrm{~A} \mathrm{~A}^{-1} ; \eta_{\mathrm{p}}-6.16 \mathrm{~lm}\right.$ $\mathrm{W}^{-1} ; \eta_{\mathrm{ex}}-4.15 \%$ at $2.8 \mathrm{~V}$ with $\left.\mathrm{CIE}(0.15,0.12)\right]$. The green device with CADPPI:Ir(ppy) 3 exhibits a maximum $L-59012 \mathrm{~cd} \mathrm{~m}^{-2} ; \eta_{\mathrm{ex}}-16.8 \% ; \eta_{\mathrm{c}}-37.3 \mathrm{~cd} \mathrm{~A}^{-1} ; \eta_{\mathrm{p}}-39.8 \mathrm{~lm} \mathrm{~W}^{-1}$ with CIE $(0.30,0.60)$ and the red device with CADPPI:Ir(MDQ) 2 (acac) shows a maximum $L-43456 \mathrm{~cd} \mathrm{~m}^{-2} ; \eta_{\mathrm{ex}}-21.9 \% ; \eta_{\mathrm{c}}-$

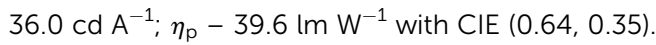

\section{Introduction}

Organic light-emitting diodes (OLEDs) have been applied in flat-panel displays and solid-state sources for the last three decades. ${ }^{1}$ For an OLED with stable emission, the current efficiency $\left(\eta_{\mathrm{c}}\right)$ is related to external quantum efficiency $\left(\eta_{\text {ex }}\right)$ power efficiency $\left(\eta_{\mathrm{p}}\right)$ is directly related to energy conversion rate and is determined by $\eta_{\mathrm{c}}$ and driving voltage $(V)$ of the devices $\left[\eta_{\mathrm{p}}=\right.$ $\left.\left(\pi \eta_{\mathrm{c}} / V\right)\right] .{ }^{2}$ By employing iridium and platinum based phosphorescent complexes and thermally activated delayed fluorescent (TADF) materials, high $\eta_{\mathrm{ex}}$ have been achieved, however, they suffer from short lifetime and roll-off efficiency and also the production cost of phosphorescent materials is unfavorable for practical applications. ${ }^{3-9}$ Therefore, a low driving voltage with high brightness becomes the major issue to achieve efficient OLEDs. ${ }^{\mathbf{1 0 , 1 1}}$ One strategy for constructing blue-emitting materials could be the integration of highenergy emissive fragments through twisted arrangements which can reduce conjugation. A twisted molecule with high thermal properties promotes the blue emission required for blue OLEDs. ${ }^{12,13}$

Department of Chemistry, Annamalai University, Annamalai nagar 608002 , Tamilnadu, India. E-mail: jtchalam2005@yahoo.co.in; Tel: +91 9443940735

$\dagger$ Electronic supplementary information (ESI) available: SI-I: figures, SI-II: solvatochromism for HLCT character, SI-III: charge-transfer indexes. See DOI: 10.1039/c9ra07509g.
Organic donor-acceptor (D-A) compounds with HLCT emissive state show high-exciton utilization efficiency $\left(\eta_{\mathrm{S}}\right)$ in fluorescent OLEDs (hot exciton model). Mixing of LE and CT states possible when LE as well as CT states are closure in energy, $\Psi\left(\mathrm{S}_{1}\right)=\Psi(\mathrm{LE})+\lambda \times \Psi(\mathrm{CT}) ; \lambda=\mid\left\langle\Psi_{\mathrm{LE}}|H| \Psi_{\mathrm{CT}}\right\rangle / E_{\mathrm{CT}}-$ $E_{\mathrm{LE}}$. The low-lying higher \% LE state provides high radiative rate $\left(k_{\mathrm{r}}\right)$ for high photoluminescence-efficiency $\left(\eta_{\mathrm{PL}}\right)$ whereas lowlying higher \% CT state provides for high $\eta_{\mathrm{S}}$ through reverse intersystem crossing (RISC) process with hot exciton model. ${ }^{\mathbf{1 4 - 2 0}}$ The larger energy gap between $\mathrm{T}_{2}$ and $\mathrm{T}_{1}$ states reduced internal conversion (IC) $\left(\mathrm{T}_{2} \stackrel{k_{\mathrm{IC}}}{\longrightarrow} \mathrm{T}_{1}\right)$ results hot RISC $\left(\mathrm{T}_{2} \stackrel{k_{\mathrm{RISC}}}{\longrightarrow} \mathrm{S}_{1} / \mathrm{S}_{2}\right)$ than cold RISC $\left(\mathrm{T}_{1} \stackrel{k_{\mathrm{RIC}}}{\longrightarrow} \mathrm{S}_{1}\right)$ : ${ }^{21}$ hot exciton with HLCT increases $\eta_{\mathrm{EQE}}$ due to coexistence of high $\eta_{\mathrm{PL}}$ and high $\eta_{\mathrm{S}}$. The external quantum efficiency $\left(\eta_{\mathrm{EQE}}\right)$ and exciton utilization efficiency $\left(\eta_{\mathrm{S}}\right)$ calculated by, $\eta_{\mathrm{EQE}}=\eta_{\mathrm{out}} \times \eta_{\mathrm{IQE}}=\eta_{\mathrm{out}} \times \eta_{\mathrm{rec}} \times \eta \square \times \Phi_{\mathrm{PL}} ; \eta_{\mathrm{s}}=$ $\eta_{\text {out }} \times \eta_{\text {rec }} \times \eta_{\text {PL }}{ }^{22,23}\left[\eta_{\text {out }}\right.$ - light-out-coupling efficiency (20\%), $\eta_{\mathrm{rc}}$ - product of the charge recombination efficiency $(100 \%), \eta_{\gamma}$ - efficiency of radiative exciton production $(25 \%)$ and $\Phi_{\mathrm{PL}}-$ photoluminescence quantum yield].

The development of high performance host materials is critical for efficient phosphorescent organic light emitting devices (PhOLEDs)and host material should have high triplet exited state energy $\left(E_{\mathrm{T}}\right)$ with good carrier transport properties to achieve efficient energy transfer from host to doped emitter to reduce the driving voltage. ${ }^{24}$ The diphenylphenanthrimidazole derivatives with electron-donating (carbazole or triphenylamine) or electron-withdrawing groups (diphenylphosphine 
oxide) with good bipolar transport ability as well as high thermal stability have been employed as hosts for highly efficient PhOLEDs. ${ }^{\mathbf{2 4 2 5}}$ The $E_{\mathrm{T}}$ energy $(\sim 2.5 \mathrm{eV})$ of diphenylphenanthrimidazole based hosts is lower compared to individual imidazole molecule owing to enlarged $\pi$-electron conjugation. ${ }^{26}$ Therefore, tuning the molecular configuration to highly twisted architecture may be an effective strategy to achieve hosts with high $E_{\mathrm{T}}$.

In line with this molecular-design strategy, we report multifunctional blue OLED materials namely, $N$-(4-(10-(1-(2,3dihydrobenzo $[b][1,4]$ dioxin-6-yl)-1H-phenanthro[9,10- $d]$ imidazol-2-yl)anthracen-9-yl)phenyl)- $N$-phenylbenzenamine

(DPIAPPB) and 2-(10-(9H-carbazol-9-yl)anthracen-9-yl)-1-(2,3dihydrobenzo[ $b][1,4]$ dioxin-6-yl)-1 $H$-phenanthro[9,10- $d]$ imid-

azole (CADPPI) used as (i) emitters in blue OLEDs and (ii) host for PHOLEDs (green and red) (Scheme 1). The DPIAPPB and CADPPI was adopted as a host to fabricate PhOLEDs which endowed high triplet energy $\left(E_{\mathrm{T}}\right)$ of these materials show high quantum yield $\left(\phi_{\text {film }}\right)$ with reduced singlet-triplet splitting $\left(\Delta_{\mathrm{ST}}\right)$. The high $E_{\mathrm{T}}$ of DPIAPPB $(2.16 \mathrm{eV})$ and CADPPI $(2.27 \mathrm{eV})$ is enough to excite green and red phosphorescent dopant. The CADPPI based device (EL - $467 \mathrm{~nm})$ shows high efficiencies $\left(\eta_{\mathrm{c}}-\right.$

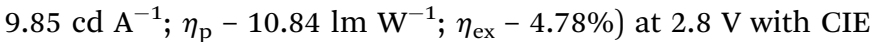
$(0.15,0.10)$ compared to DPIAPPB device $(\mathrm{EL}-472 \mathrm{~nm})\left(\eta_{\mathrm{c}}-\right.$ $\left.6.56 \mathrm{~cd} \mathrm{~A}^{-1} ; \eta_{\mathrm{p}}-6.16 \mathrm{~lm} \mathrm{~W}^{-1} ; \eta_{\mathrm{ex}}-4.15 \%\right)$ at $2.8 \mathrm{~V}$ with CIE
$(0.15,0.12)$. The green device based on CADPPI:Ir(ppy $)_{3}$ exhibit maximum $L-59012 \mathrm{~cd} \mathrm{~m}^{-2} ; \eta_{\mathrm{ex}}-16.8 \% ; \eta_{\mathrm{c}}-37.3 \mathrm{~cd} \mathrm{~A}^{-1} ; \eta_{\mathrm{p}}-$ $39.8 \mathrm{~lm} \mathrm{~W}^{-1}$ with $\operatorname{CIE}(0.30,0.60)$ and red device with CADPPI:Ir(MDQ) $)_{2}$ (acac) exhibit maximum $L-43456 \mathrm{~cd} \mathrm{~m}^{-2}$; $\eta_{\text {ex }} 21.9 \% ; \eta_{\mathrm{c}}-36.0 \mathrm{~cd} \mathrm{~A}{ }^{-1} ; \eta_{\mathrm{p}}-39.6 \mathrm{~lm} \mathrm{~W}^{-1}$ with CIE (0.64, 0.35). These results are employed to design low cost OLEDs using subtle molecular tuning with HLCT emissive state.

\section{Experimental section}

\subsection{Measurements}

${ }^{1} \mathrm{H}$ and ${ }^{13} \mathrm{C}$ NMR were recorded at $298 \mathrm{~K}$ on Bruker $(400 \mathrm{MHz})$ spectrometer using $\mathrm{CDCl}_{3}$ as solvent and TMS as internal standard and MALDI-TOF MS mass spectra was recorded on LCMS VL SD Agilent instrument. UV-vis absorption in solution and film were measured on Lambda 35 spectrophotometer with integrated sphere (RSA-PE-20) instrument. Emission characteristics were investigated with PerkinElmer LS55 spectrometer. Absolute quantum efficiencies of solution and film were determined with fluorescence spectrometer Model-F7100 with integrating sphere. Thermogravimetric analysis (TGA) and differential scanning calorimetric (DSC) were under taken with PerkinElmer thermal analysis system and NETZSCH-DSC-204, respectively with heating rate $10{ }^{\circ} \mathrm{C} \mathrm{min}^{-1}$ and $\mathrm{N}_{2}$ flow rate $100 \mathrm{~mL} \mathrm{~min}{ }^{-1}$. Fluorescence lifetime was estimated from time

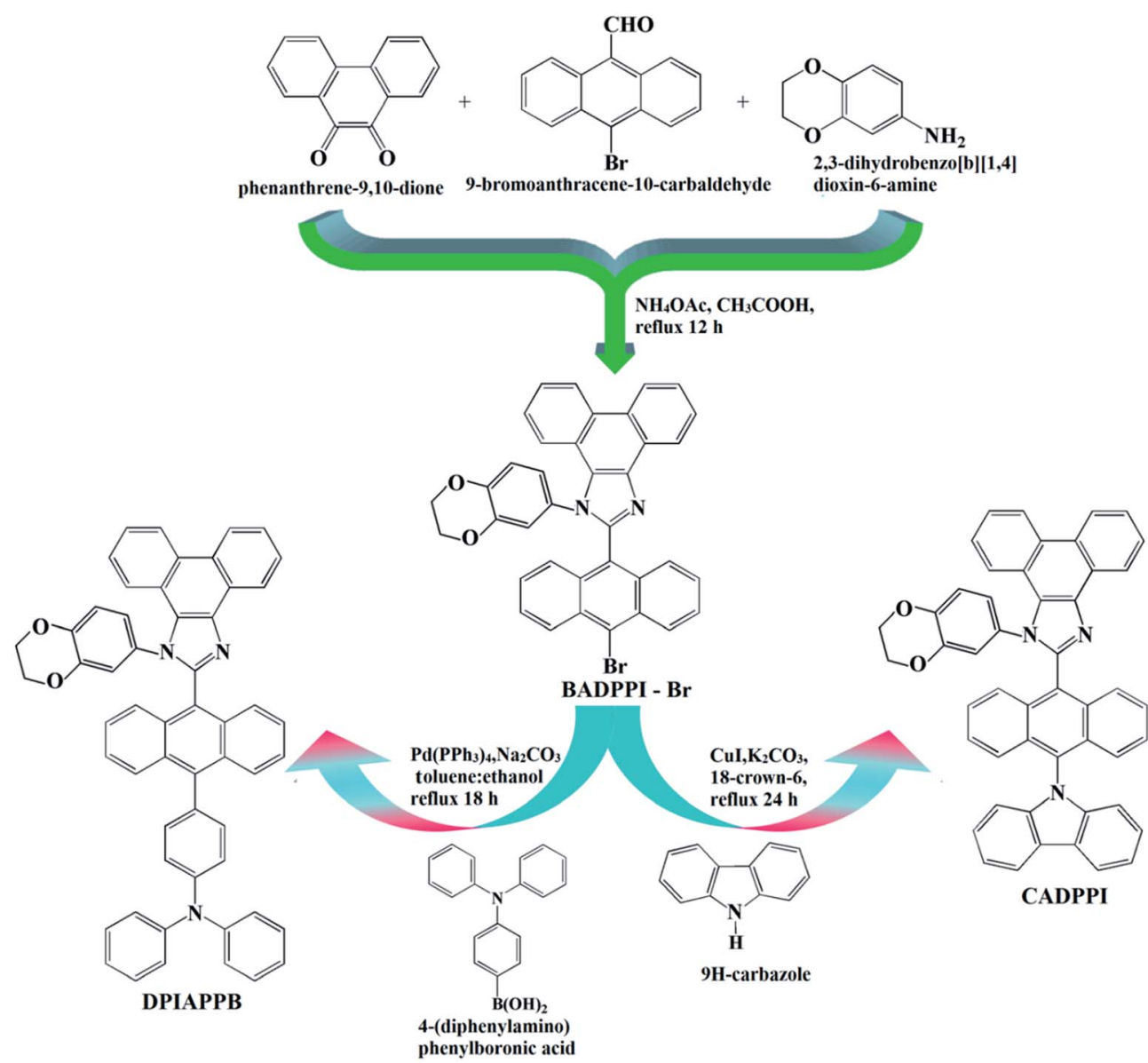

Scheme 1 Synthetic route of CADPPI and DPIAPPB. 
correlated-single-photon counting (TCSPC) on Horiba Fluorocube-01-NL lifetime system: nano LED is excitation source with TBX-PS is detector. Electrochemical studies were performed with potentiostate $\mathrm{CHI} 630 \mathrm{~A}$ electrochemical analyzer $\left(\mathrm{Ag} / \mathrm{Ag}^{+}\right.$as reference electrode, platinum electrode is working electrode and platinum wire is counter electrode, scan $100 \mathrm{mV} \mathrm{s}^{-1}$ ). Ferrocene was used as internal standard with highest occupied molecular orbital energy (HOMO) of $-4.80 \mathrm{eV}$ and $0.1 \mathrm{M}$ tetrabutylammonium perchlorate in $\mathrm{CH}_{2} \mathrm{Cl}_{2}$ as supporting electrolyte. The HOMO energies $\left(E_{\mathrm{HOMO}}\right)$ were calculated from $E_{\text {HоMо }}=-\left(E_{\mathrm{ox}}+4.8 \mathrm{eV}\right)$ and LUMO energies were estimated from $E_{\mathrm{LUMO}}=\left(E_{\mathrm{red}}-4.8 \mathrm{eV}\right)$.

\subsection{Computational details}

The ground $\left(\mathrm{S}_{0}\right)(\mathrm{DFT}) /$ excited $\left(S_{n}^{*}\right)$ (TD-DFT) characteristics were studied using Gaussian 09 program ${ }^{27}$ and Multifunctional wavefunction analyzer (Multiwfn). The natural transition orbitals (NTOs) were analyzed with dominant hole-particle pair $\left(\mathrm{S}_{1}-\mathrm{S}_{5}\right.$ and $\mathrm{T}_{1}-\mathrm{T}_{5}$ states $)$ contributions and associated transition weights. Multiwfn software was employed for wave function of electron-hole pair from transition density matrix (TDM) by TDDFT and was plotted in two-dimensional (2D) color-filled map for easily differentiating ground state from excited-state character $\left(\mathrm{S}_{1}-\mathrm{S}_{5}\right)$.

\subsection{Synthesis of 2-(10-bromoanthracen-9-yl)-1-(2,3- dihydrobenzo $[b][1,4]$ dioxin-6-yl)-1H-phenanthro $[9,10-d]$ imidazole (BADPPI)}

A mixture of phenanthrene-9,10-dione (0.42 g, $2.0 \mathrm{mmol}), 10-$ bromoanthracene-9-carbaldehyde $(0.57 \mathrm{~g}, 2.0 \mathrm{mmol})$, ammonium acetate $(0.62 \mathrm{~g}, 8.0 \mathrm{mmol})$ and 1,4-benzodioxane-6-amine (4.65 g, $50 \mathrm{mmol})$ in $20 \mathrm{~mL}$ acetic acid was refluxed $\left(120^{\circ} \mathrm{C} ; 12 \mathrm{~h}\right.$; $\mathrm{N}_{2}$ stream). By column chromatography the yellow solid was purified. Yield 70\%. ${ }^{1} \mathrm{H}$ NMR (400 $\left.\mathrm{MHz}, \mathrm{CDCl}_{3}, \mathrm{ppm}\right): \delta 4.23-$ $4.34(\mathrm{~m}, 4 \mathrm{H}), 6.74(\mathrm{~d}, 3 \mathrm{H}), 7.16(\mathrm{t}, J=7.8 \mathrm{~Hz}, 2 \mathrm{H}), 7.27(\mathrm{~d}, J=$ $8.6 \mathrm{~Hz}, 1 \mathrm{H}), 7.28(\mathrm{~d}, J=8.0 \mathrm{~Hz}, 2 \mathrm{H}), 7.38(\mathrm{t}, J=8.2 \mathrm{~Hz}, 2 \mathrm{H}), 7.49-$ $7.55(\mathrm{~m}, 3 \mathrm{H}), 7.59-7.65(\mathrm{~m}, 3 \mathrm{H}), 8.43-8.90(\mathrm{~m}, 3 \mathrm{H}) .{ }^{13} \mathrm{C}$ NMR $\left(100 \mathrm{MHz}, \mathrm{CDCl}_{3}\right): \delta 63.31,64.29,101.59,114.50,115.89,122.39$, 122.46, 126.49, 126.58, 126.61, 126.63, 126.69, 127.55, 127.65, 127.88, 128.21, 129.30, 131.49, 131.57, 135.46, 146.19, 147.60, 149.38. MALDI-TOF MS: $m / z .606 .20[\mathrm{M}]^{+}$(calcd: 606.37). Anal. calcd (\%) for $\mathrm{C}_{37} \mathrm{H}_{23} \mathrm{~N}_{2} \mathrm{O}_{2} \mathrm{Br}: \mathrm{C}, 73.15 ; \mathrm{H}, 3.82 ; \mathrm{N}, 4.61$. Found: $\mathrm{C}$, $73.10 ; \mathrm{H}, 3.67 ; \mathrm{N}, 4.57$.

2.4. Synthesis of 2-(10-(9H-carbazol-9-yl)anthracen-9-yl)-1(2,3-dihydrobenzo[b][1,4] dioxin-6-yl)-1H-phenanthro[9,10- $d]$ imidazole (CADPPI)

A mixture of BADPPI (3.0 mmol), $9 H$-carbazole $(7.5 \mathrm{mmol}), \mathrm{CuI}$ (10.0 mg), $\mathrm{K}_{2} \mathrm{CO}_{3}(6.0 \mathrm{mmol}), 18$-crown-6 (0.05 mmol) and distilled water $(10 \mathrm{~mL})$ was refluxed $\left(90^{\circ} \mathrm{C} ; 16 \mathrm{~h} ; \mathrm{N}_{2}\right.$ stream). The reaction was quenched by an ice water followed by extraction with dichloromethane. By column chromatography the yellow solid was purified. Yield $68 \%$. ${ }^{1} \mathrm{H}$ NMR (400 $\left.\mathrm{MHz}, \mathrm{CDCl}_{3}, \mathrm{ppm}\right)$ : 4.0-4.29 (m, 4H), 6.69 (t, 3H), 7.02-7.32 (m, 4H), 7.40-7.89 (m, $12 \mathrm{H}), 8.10(\mathrm{~d}, J=8.0 \mathrm{~Hz}, 2 \mathrm{H}), 8.65-8.90(\mathrm{~m}, 6 \mathrm{H}) .{ }^{13} \mathrm{C}$ NMR $(100$ $\left.\mathrm{MHz}, \mathrm{CDCl}_{3}\right): \delta 65.01,101.58,113.98,115.99,119.01,120.11$,
121.05, 121.19, 122.13, 122.28, 126.53, 127.61, 128.31, 129.80, 132.13, 139.88, 146.21, 147.63. MALDI-TOF MS: $m / z .692 .20[\mathrm{M}]^{+}$ (calcd: 692.38). Anal. calcd (\%) for $\mathrm{C}_{49} \mathrm{H}_{31} \mathrm{~N}_{3} \mathrm{O}_{2}: \mathrm{C}, 84.80 ; \mathrm{H}$, 4.49; N, 6.01. Found: C, 84.65; H, 4.38; N, 6.58.

\subsection{Synthesis of $N$-(4-(10-(1-(2,3-dihydrobenzo $[b][1,4]$ dioxin- 6-yl)-1H-phenanthro[9,10- $d]$ imidazol-2-yl)anthracen-9-yl) phenyl)- $N$-phenylbenzenamine (DPIAPPB)}

A mixture of BADPPI (3.0 mmol), 4-(diphenylamino)phenylboronic acid (1.04 g, $3.6 \mathrm{mmol}), \mathrm{Pd}\left(\mathrm{PPh}_{3}\right)_{4}(0.15 \mathrm{mmol}), \mathrm{K}_{2} \mathrm{CO}_{3}$ (45 mmol), toluene : ethanol $(2: 1)$ with distilled water $(10 \mathrm{~mL})$ was refluxed $\left(90{ }^{\circ} \mathrm{C} ; 16 \mathrm{~h} ; \mathrm{N}_{2}\right.$ stream). By column chromatography the yellow solid was purified. Yield 70\%. ${ }^{1} \mathrm{H}$ NMR $(400$ $\left.\mathrm{MHz}, \mathrm{CDCl}_{3}, \mathrm{ppm}\right): 4.30-4.36(\mathrm{~m}, 4 \mathrm{H}), 6.70(\mathrm{~d}, 3 \mathrm{H}), 7.11(\mathrm{t}, J=$ $8.0 \mathrm{~Hz}, 2 \mathrm{H}), 7.15-7.25(\mathrm{~m}, 12 \mathrm{H}), 7.30-7.48(\mathrm{~m}, 11 \mathrm{H}), 7.58(\mathrm{~d}, J=$ $8.8 \mathrm{~Hz}, 2 \mathrm{H}), 8.83-8.90(\mathrm{~m}, 3 \mathrm{H}) .{ }^{13} \mathrm{C} \mathrm{NMR}\left(100 \mathrm{MHz}, \mathrm{CDCl}_{3}\right)$ : $\delta 63.21,101.10,114.51,115.91,122.41,122.73,123.25,123.28$, 126.31, 127.63, 128.80, 129.68, 129.79, 131.23, 134.89, 139.91, 141.15, 146.21, 147.68. MALDI-TOF MS: $m / z$. 771.25 [M] $]^{+}$(calcd: 771.39). Anal. calcd (\%) for $\mathrm{C}_{55} \mathrm{H}_{37} \mathrm{~N}_{3} \mathrm{O}_{2}: \mathrm{C}, 85.50 ; \mathrm{H}, 4.80 ; \mathrm{N}$, 5.46. Found: C, 85.45; H, 5.38; N, 5.36.

\subsection{Device fabrication and measurement}

Before device fabrication, the ITO glass (resistance $20 \Omega \mathrm{sq}^{-1}$ ) were cleaned by using acetone followed by deionized water and isopropanol, dried at $120{ }^{\circ} \mathrm{C}$ and employed UV-zone (20 min) and transferred into deposition system. The devices were fabricated by vacuum deposition method $\left(4 \times 10^{-5}\right.$ mbar $)$. Evaporation rates $2-4 \AA \mathrm{s}^{-1}$ (organic materials) and $0.1 \AA \mathrm{s}^{-1}$ (LiF) and $4 \AA^{-1} \mathrm{~s}^{-1}$ (metal electrodes) were applied. The thickness of each deposition layer was monitored with quartz crystal thickness monitor. The EL spectra and CIE coordinates were recorded with (USB-650-VIS-NIR spectrometer Ocean Optics, Inc, USA).The current density-voltage-luminance $(J-V-L)$ characteristics were performed simultaneously by using a computercontrolled source meter (Keithley 2450) equipped with light intensity meter LS-110. The EQEs were determined using luminance, current density and EL spectrum, assuming Lambertian distribution.

To gain insight into the hole and electron-transporting abilities of DPIAPPB and CADPPI, single-carrier devices with configuration of ITO/NPB $(8 \mathrm{~nm}) /$ DPIAPPB or CADPPI $(40 \mathrm{~nm}) /$ NPB (8 nm)/Al (100 nm) (hole-only device) was fabricated: NPB (LUMO: $-2.3 \mathrm{eV})^{28}$ in the hole-only device can prevent electron injection from $\mathrm{Al}$ cathode $\left(E_{\mathrm{f}}-4.3 \mathrm{eV}\right)$ to the DPIAPPB or CADPPI layer ${ }^{29}$ and ITO/TPBi $(8 \mathrm{~nm}) /$ DPIAPPB or CADPPI (40 $\mathrm{nm}) / \mathrm{TPBi}(8 \mathrm{~nm}) / \mathrm{LiF}(1 \mathrm{~nm}) / \mathrm{Al}(100 \mathrm{~nm})$ (electron-only device): TPBi (HOMO: $-6.2 \mathrm{eV})^{30}$ in the electron-only devices with ITO $\left(E_{\mathrm{f}}-4.8 \mathrm{eV}\right)$ as the anode can prevent hole injection were fabricated. ${ }^{31}$ To evaluate the potential application of these compounds as emitting materials, non-doped OLEDs with configuration of ITO/NPB (60 nm)/DPIAPPB and CADPPI (20 $\mathrm{nm}) / \mathrm{LiF}(1 \mathrm{~nm}) / \mathrm{Al}(100 \mathrm{~nm})$ have been fabricated. Green device: ITO/NPB (40 nm)/TCTA (5 nm)/DPIAPPB (30 nm): 5 wt\% Ir(ppy) or CADPPI (30 nm): $5 \mathrm{wt} \% \operatorname{Ir}(\mathrm{ppy})_{3} / \mathrm{TPBi}(50 \mathrm{~nm}) / \mathrm{LiF}(1 \mathrm{~nm}) / \mathrm{Al}$ $(100 \mathrm{~nm})$ and Red device: ITO/NPB (40 nm)/TCTA $(5 \mathrm{~nm}) /$ 
DPIAPPB $(30 \mathrm{~nm}): 8 \mathrm{wt} \% \operatorname{Ir}(\mathrm{MDQ})_{2}$ (acac) or CADPPI: $8 \mathrm{wt} \%$ $\operatorname{Ir}(\mathrm{MDQ})_{2}(\mathrm{acac}) / \mathrm{TPBi}(50 \mathrm{~nm}) / \mathrm{LiF}(1 \mathrm{~nm}) / \mathrm{Al}(100 \mathrm{~nm})$ were also fabricated.

\section{Results and discussion}

The synthetic route for the emissive materials is displayed in Scheme 1: efficient blue emitters namely, $N$-(4-(10-(1-(2,3-dihydrobenzo[ $b][1,4]$ dioxin-6-yl)-1H-phenanthro[9,10- $d]$ imidazol-2yl)anthracen-9-yl)phenyl)- $N$-phenylbenzenamine

(DPIAPPB) and 2-(10-(9H-carbazol-9-yl)anthracen-9-yl)-1-(2,3-dihydrobenzo $[b][1,4]$ dioxin-6-yl)-1H-phenanthro[9,10- $d]$ imidazole (CADPPI) were synthesized by Suzuki-coupling reaction with appreciable yield 70 and $68 \%$ and characterized by ${ }^{1} \mathrm{H}$ and ${ }^{13} \mathrm{C}$ NMR, high resolution mass and elemental analysis. The carbazole (weak electron-donor) in CADPPI increased the \% LE component in HLCT emissive state which results high photoluminescence efficiency $\left(\eta_{\mathrm{PL}}\right)$ when compared to DPIAPPB.

\subsection{Potential energy scan (PES)}

The ground $\left(\mathrm{S}_{0}\right)$ and excited $\left(\mathrm{S}_{1}\right)$ state geometries of D-ח-A compounds, CADPPI and DPIAPPB were optimized with DFT/ B3LYP/6-31G (d,p) and TD-DFT/B3LYP/6-31G (d,p) methods using Gaussian-09 (Fig. 1). The twist angles $\left(\theta^{\circ}\right)\left[\mathrm{N}-\theta^{\circ}\right.$ (phenanthrimidazole and dihydrobenzodioxin), $\mathrm{C}-\theta^{\circ}$ (phenanthrimidazole and anthracene) and $\mathrm{A}-\theta^{\circ}$ (anthracene and triphenylamine (DPIAPPB)/carbazole (CADPPI))] play a vital role in frontier molecular orbitals electron overlap in ground and excited states. The ground state energy of D- $\Pi-\mathrm{A}$ materials reveal that $\mathrm{N}-\theta^{\circ}$ was limited at room temperature $\left(k_{\mathrm{BT}}, 9.5 \mathrm{meV}\right)$ (DPIAPPB-82. $6^{\circ}-89.8^{\circ}$ :CADPPI-86. $7^{\circ}-89.6^{\circ}$ ); C- $\theta^{\circ}$ (DPIAPPB$89.6^{\circ}-91.8^{\circ}$ :CADPPI-93. $7^{\circ}-99.0^{\circ}$ ); $\quad \mathrm{A}-\theta^{\circ} \quad$ (DPIAPPB-102. $3^{\circ}-$ $108.6^{\circ}$ :CADPPI- $156^{\circ}$ ) and rises steeply when the twist angle was out of this range ${ }^{32}$ (Fig. 1).The larger twist angle $\left(\mathrm{A}-\theta^{\circ}\right)$ of CADPPI compared to DPIAPPB is due to the stronger repulsion between the two adjacent hydrogen atoms in carbazole and anthracene ring because of stronger rigidity of $\mathrm{Cz}$ than TPA.

The excited state $\left(\mathrm{S}_{1}\right)$ twist angles, $\mathrm{N}-\theta^{\circ}, \mathrm{C}-\theta^{\circ}$ and $\mathrm{A}-\theta^{\circ}$ of CADPPI and DPIAPPB are increased than ground state $\left(\mathrm{S}_{0}\right)$ twist angles. Only small changes in the geometry of $\mathrm{Cz}$ in CADPPI from $S_{0} \rightarrow S_{1}$ was observed compared to TPA unit in DPIAPPB which minimised non-radiation leads to enhancement of $\eta_{\mathrm{PL}}{ }^{32}$ The potential energy surface of twisted geometry of CADPPI at ground and excited states (Fig. S1 $\dagger$ ) reveal that the CADPPI require small energy to form excited state excimer corresponding to increased interplanar separation of carbazole from linker (1.45 ̊ to $1.4700 \AA$ A: $156.6^{\circ}$ to $158.0^{\circ}$ : Fig. 1 ) and then only small energy needs to return to an equilibrium geometry at ground state. The rigid geometry of CADPPI minimized the nonradiation and enhanced the emission and lifetime of CADPPI exciton leads to higher photoluminescence efficiency. ${ }^{32,33}$

The CADPPI and DPIAPPB molecules show twisted structure which is essential for separating HOMO and LUMO distribution effectively which enhanced the excition utilization $\left(\eta_{\mathrm{s}}\right)$ through efficient up conversion of non-radiative triplet to radiative singlet. The overlap between HOMO and LUMO is extremely small for CADPPI ensuring the small $\Delta E_{\mathrm{ST}}$ and ensures fairish radiative decay from intramolecular CT exciton..$^{34}$ The small inter ring torsion angles of highly twisted molecular conformation suppress the intermolecular $\pi-\pi$ stacking in solid state and thus, fluorescence quenching was suppressed. Also the extent of conjugation is reduced, thus, the amount of charge transfer (CT) is increased. This is reflected in solvatochromic studies. The non-coplanar twisted architecture of CADPPI and DPIAPPB suppresses red shift and high $\eta_{\mathrm{ex}}$ was harvested in film by restraining intermolecular interaction. ${ }^{35-38}$
Molecular structure

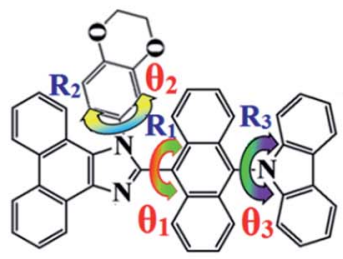

CADPPI

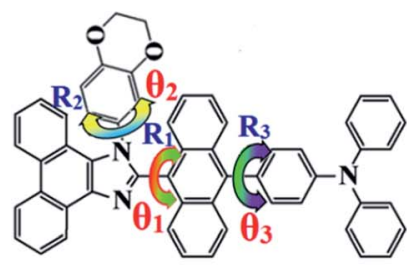

DPIAPPB
Ground state
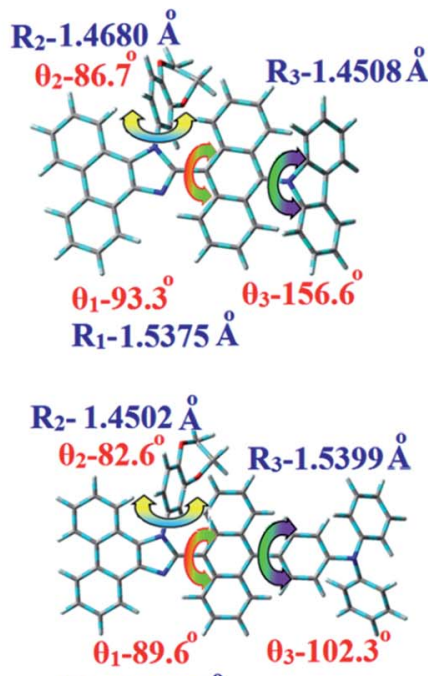

$\mathbf{R}_{1}-1.5201 \AA$
Excited state
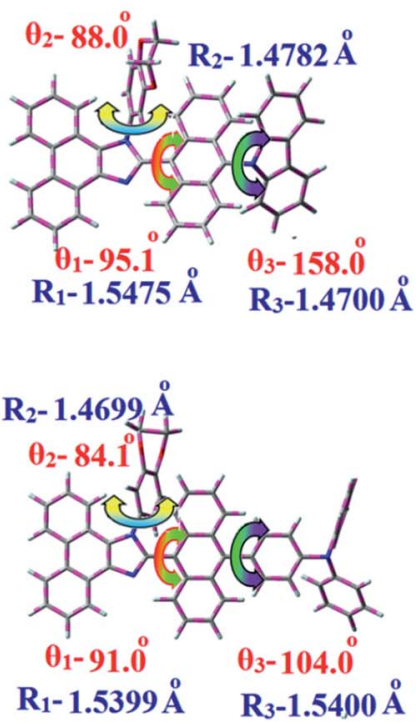

Fig. 1 Molecular structure, ground and excited state geometries with dihedral angles of CADPPI and DPIAPPB. 


\subsection{Thermal and electrochemical properties}

The incorporation of highly rigid bulky moiety at imidazole carbon and bulky side capping at imidazole nitrogen enlarged the size and increased their thermal stability. The excellent thermal stability of these new donor-spacer-acceptor compounds $\left(T_{\mathrm{d}}-504{ }^{\circ} \mathrm{C}-\mathrm{CADPPI}\right.$ and $T_{\mathrm{d}}-482{ }^{\circ} \mathrm{C}-$ DPIAPPB $)$ was analyzed by high decomposition temperatures $\left(T_{\mathrm{d}}: 5 \%\right.$ weight loss) (Table 1: Fig. $\mathrm{S} 2 \dagger$ ). The high $T_{\mathrm{d}}$ reveals that these compounds would be capable of enduring vacuum thermal sublimation process. Both compounds show high glass transition temperature $\left(T_{\mathrm{g}}-220{ }^{\circ} \mathrm{C}-\mathrm{CADPPI}\right.$ and $T_{\mathrm{g}}-210{ }^{\circ} \mathrm{C}-$ DPIAPPB) indicating that introduction of rigid phenanthrimidazole moiety improves greatly their morphological stability and the melting point $\left(T_{\mathrm{m}}\right)$ of CADPPI and DPIAPPB are determined as $385{ }^{\circ} \mathrm{C}$ and $388^{\circ} \mathrm{C}$, respectively. The improved $T_{\mathrm{g}}$ was probably due to the interaction of substituent at C2- and N1 with phenanthrimidazole core which can induce more condensed molecular packing. The higher $T_{\mathrm{g}}$ implicates that they could form morphologically stable amorphous film upon thermal evaporation, reduces phase separation upon heating and prolonging the lifetime of devices which is highly important for OLEDs. Among the donor-spacer-acceptor compounds, CADPPI exhibit higher thermal stability than that of DPIAPPB (Fig. S2 $\dagger$ ) because of stronger rigidity of $\mathrm{Cz}$ than TPA which will be in favor of OLED stability. The thermal morphological stability of thin film of these compounds was examined by AFM measurement which show that DPIAPPB and CADPPI film exhibit fairly smooth surface morphology with a roughness of $0.24 \mathrm{~nm}$ (DPIAPPB) and $0.20 \mathrm{~nm}$ (CADPPI), which was nearly unchanged after annealing $\left(90{ }^{\circ} \mathrm{C} ; 2 \mathrm{~h}\right)$. These results indicate that DPIAPPB and CADPPI could form very stable and smooth film to support EL device fabrication (Fig. 6).

Electrochemical characterization of CADPPI and DPIAPPB were investigated by cyclic voltammetry and theoretical calculation. ${ }^{39,40}$ Both compounds show a reversible reduction and a quasi-reversible oxidation: the reduction onset potentials of DPIAPPB and CADPPI are -2.22 and $-2.23 \mathrm{~V}$, respectively. The oxidation onset potential of DPIAPPB $(+0.32 \mathrm{~V})$ is much lower than CADPPI $(+0.50 \mathrm{~V})$. Based on redox onset potentials, $E_{\text {Hомо }}$ $=E_{\mathrm{ox}}+4.8 \mathrm{eV}$ and $E_{\mathrm{LuMO}}=E_{\text {red }}-4.8 \mathrm{eV}$ were calculated by assuming the energy of ferrocene as $4.8 \mathrm{eV}$ below the vacuum level. ${ }^{41}$ The $E_{\text {LUMO }}$ of DPIAPPB $(-2.58 \mathrm{eV})$ and CADPPI $(-2.57$ eV) match well with the electron-transporting material, bis[2-(2hydroxyphenyl)-pyridine]beryllium, LUMO $=-2.6 \mathrm{eV}$ (ref. 40) suggesting that they may used as electron-transporting layer and non doped-emitting layer. The $E_{\text {Hомо }}$ are deduced to be $-5.12 \mathrm{eV}$ for DPIAPPB and $-5.30 \mathrm{eV}$ for CADPPI. This reflects the more balanced carrier injection properties of these materials.

The LUMOs of DPIAPPB and CADPPI have similar distributions, being predominantly located on the anthracene unit. However, the HOMO distributions are significantly different. For DPIAPPB, the HOMO is located on anthracene and TPA units, while that of CADPPI is mainly located on anthracene and phenanthrimidazole moieties. The calculated LUMO levels are close whereas HOMO energy of DPIAPPB is higher than CADPPI (Fig. S3 $\dagger$ ). These trends are consistent with CV data. As deduced from much easier electrochemical oxidation of TPA (oxidation potential: $c a$. $0.48 \mathrm{~V}$ vs. $\left.\mathrm{Fc} / \mathrm{Fc}^{+}\right)^{42}$ than phenanthrimidazole (oxidation potential: $c a .0 .84 \mathrm{~V} v s . \mathrm{Fc} / \mathrm{Fc}^{+}$), ${ }^{43}$ the TPA unit should be more electron rich than phenanthrimidazole unit. As a result, TPA-anthracene moiety in DPIAPPB is more electron rich than anthracene-phenanthrimidazole moiety in CADPPI so that higher HOMO level of DPIAPPB is rational.

\subsection{Photophysical properties and HLCT character}

The optical spectra of DPIAPPB and CADPPI in dichloromethane $\left(1 \times 10^{-5} \mathrm{M}\right)$ were recorded in solution and neat film (Fig. 2: Table 1). ${ }^{44}$ The strong and sharp absorption around $241 \mathrm{~nm}$ is due to $\pi-\pi^{*}$ transition originates from phenyl to phenanthrimidazole ring and the absorption bands, ranging from 332 to $361 \mathrm{~nm}$ are attributed to $\pi-\pi^{*}$ transition of conjugated molecular framework. The shoulder peak at longer wavelength around $358 \mathrm{~nm}$ is due to ICT from donor to acceptor

Table 1 Optical, thermal properties and device performances of CADPPI and DPIAPPB

\begin{tabular}{lll}
\hline Emitters & CADPPI & DPIAPPB \\
\hline$\lambda_{\mathrm{ab}}(\mathrm{nm})(\mathrm{sol} / \mathrm{film})$ & $241,332,358 / 243,338,361$ & $246,348,361 / 252,360,378$ \\
$\lambda_{\mathrm{em}}(\mathrm{nm})(\mathrm{sol} / \mathrm{film})$ & $450 / 468$ & $466 / 473$ \\
$T_{\mathrm{g} / T_{\mathrm{m}} / T_{\mathrm{d} 5}\left({ }^{\circ} \mathrm{C}\right)}$ & $220 / 385 / 504$ & $210 / 388 / 482$ \\
$\phi(\mathrm{soln} / \mathrm{film})$ & $0.91 / 0.83$ & $0.82 / 0.70$ \\
$\mathrm{HOMO} / \mathrm{LUMO}(\mathrm{eV})$ & $-5.30 /-2.57$ & $-5.12 /-2.58$ \\
$E_{\mathrm{g}}(\mathrm{eV})$ & -2.73 & -2.54 \\
$\tau(\mathrm{ns})$ & 2.51 & 2.62 \\
$k_{\mathrm{r}} \times 10^{8}\left(\mathrm{~s}^{-1}\right)$ & 3.6 & 3.1 \\
$k_{\mathrm{nr}} \times 10^{8}\left(\mathrm{~s}^{-1}\right)$ & 0.3 & 0.7 \\
$V(\mathrm{~V})$ & 2.8 & 2.8 \\
$L\left(\mathrm{~cd} \mathrm{~m}{ }^{-2}\right)$ & 52823 & 38625 \\
$\eta_{\mathrm{ex}}(\%)$ & 4.78 & 4.15 \\
$\eta_{\mathrm{c}}\left(\mathrm{cd} \mathrm{A} \mathrm{A}^{-1}\right)$ & 9.85 & 6.56 \\
$\eta_{\mathrm{p}}\left(\mathrm{lm} \mathrm{W}{ }^{-1}\right)$ & 10.84 & 6.16 \\
$\mathrm{CIE}(x, y)$ & $0.15,0.10$ & $0.15,0.12$ \\
EL $(\mathrm{nm})$ & 467 & 472
\end{tabular}



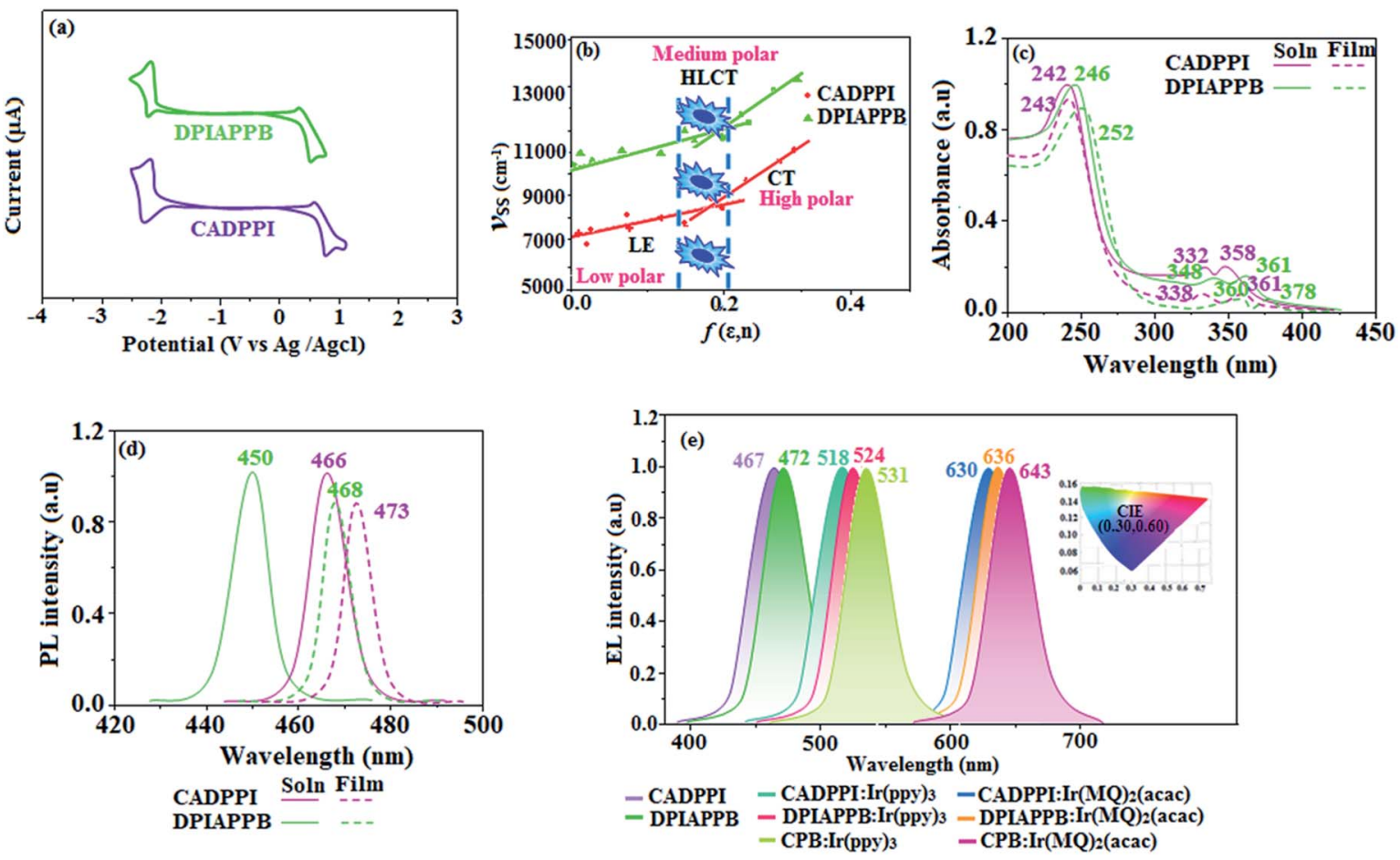

Fig. 2 Cyclic voltammogram (a); Lippert-Mataga plot (b); normalized absorption (c), emission spectra (d) and EL spectra (e) (inset: ClE coordinates) of CADPPI and DPIAPPB.

unit. $^{45}$ The D- $\pi$-A derivatives (DPIAPPB and CADPPI) exhibit higher blue shift with higher molar absorptivity when compared to their parent compound (BADPPI) due to the presence of strong and weak electron donor, triphenylamine (DPIAPPB) and carbazole (CADPPI) moiety. The extinctioncoefficient $\left(\varepsilon_{\max }\right)$ of $\mathrm{D}-\pi-\mathrm{A}$ molecules is higher due to increase of conjugation length. ${ }^{\mathbf{4 6 , 4 7}}$ The CADPPI and DPIAPPB show very strong absorption at $241 \mathrm{~nm}\left(\varepsilon_{\max }=41493 \mathrm{~cm}^{-1} \mathrm{M}^{-1}\right)$ and $246 \mathrm{~nm}\left(\varepsilon_{\max }=40650 \mathrm{~cm}^{-1} \mathrm{M}^{-1}\right)$ on comparison to parent compound BADPPI due to ICT transition from donor to acceptor (Fig. 2). The film state of blue emissive materials show absorption at $243 \mathrm{~nm}$ (CADPPI) and $252 \mathrm{~nm}$ (DPIAPPB) and the small shift shows the existence of weak $\pi-\pi *$ intermolecular stacking. ${ }^{48}$ The solution/thin film PL spectra of CADPPI and DPIAPPB show emission maxima at 450/468 and 466/473 nm, respectively (Fig. 2). The solvatochromic red-shift of $62 \mathrm{~nm}$ (DPIAPPB) and $40 \mathrm{~nm}$ (CADPPI) confirmed the highly polar nature of low-lying CT state (Fig. S4†). ${ }^{49,50}$ The red shifted emission is due to twisted conformation of DPIAPPB and CADPPI which leads to easier charge transfer from donor to accept via anthracene linker. The intramolecular charge transfer is further confirmed by molecular electrostatic potential (MEP) (Fig. S3†).

The PL spectra of CADPPI and DPIAPPB show red shift due to the strong CT character of the excited state than the ground state and stabilized by polar solvents. ${ }^{51,52}$ The emission of CADPPI and DPIAPPB is observed at 468 and $473 \mathrm{~nm}$ in solid with full-width at half-maximum (FWHM) is around $30 \mathrm{~nm}$ : the red-shift cannot be due to aggregation in solid state and might be from change in excited state configuration. ${ }^{53}$ The small red shift in film of DPIAPPB and CADPPI compared to solution show suppressed $\pi-\pi^{*}$ stacking. ${ }^{54}$ The emission of DPIAPPB and CADPPI gives blue-shift relative to their parent compound which is in controversy to the general observation i.e., extension of $\pi$-conjugation leads to red shifted emission. ${ }^{52}$ In addition to that there is an overlap between UV and PL spectra of both DPIAPPB and CADPPI because of enhanced LE character in DPIAPPB and CADPPI than their parent compound.

Compared with DPIAPPB, CADPPI exhibit higher blue shift in absorption and emission attributed to poor electron donor ability of $\mathrm{Cz}$ relative to TPA. The increase of LE composition with decrease of CT in $\mathrm{S}_{1}$ emissive HLCT state is likely to be the reason for blue shift. The FWHM in the absorption spectrum of CADPPI $(24 \mathrm{~nm})$ is narrowed compared to DPIAPPB $(31 \mathrm{~nm})$ (Fig. S5 $\dagger$ ). This observation informed that decreased CT component of CADPPI in $S_{1}$ state which is in good agreement with NTO for $S_{0} \rightarrow S_{1}$ transition. Solvatochromic shifts show the low-lying $\mathrm{S}_{1}$ excited state of DPIAPPB and CADPPI possess CT character. ${ }^{55,56}$ The \% CT in $\mathrm{S}_{1}$ state of CADPPI (65\%) is lower than DPIAPPB (85\%) whereas \% LE character of CADPPI (35\%) is higher than DPIAPPB (15\%) (Table 2). In $\mathrm{S}_{0}-\mathrm{S}_{1}$ and $\mathrm{S}_{0}-\mathrm{S}_{2}$ transitions, the HLCT was composed with CT and LE state and exhibit larger oscillator strength $\left[f_{\mathrm{S}_{0}-\mathrm{S}_{1}}=0.5041\right.$ (CADPPI): 0.4041 (DPIAPPB) and $f_{\mathrm{S}_{0}-\mathrm{S}_{2}}=0.1882$ (CADPPI): 0.1644 (DPIAPPB)] compared to other transitions $\mathrm{S}_{0}-\mathrm{S}_{\mathrm{n}}(n=3,4 \ldots)$ as a result of major LE character in the HLCT state (Fig. S6 $\dagger^{-}$

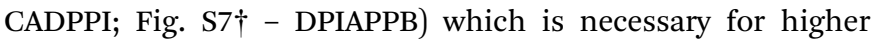
efficiency OLEDs. ${ }^{57}$ 
Table 2 Percentage transition of LE and CT of CADPPI and DPIAPPB

\begin{tabular}{lllll}
\hline & \multicolumn{2}{l}{ CADPPI } & & DPIAPPB \\
\cline { 2 - 4 } Transition $(\%)$ & Singlet $\left(\mathrm{S}_{1}-\mathrm{S}_{10}\right)$ & Triplet $\left(\mathrm{T}_{1}-\mathrm{T}_{10}\right)$ & Singlet $\left(\mathrm{S}_{1}-\mathrm{S}_{10}\right)$ & 85 \\
CT & 65 & 60 & 15 & 75 \\
LE & 35 & 40 & Triplet $\left(\mathrm{T}_{1}-\mathrm{T}_{10}\right)$ \\
\end{tabular}

The DPIAPPB and CADPPI ground state energy and their electron density delocalization at twist angle of $50^{\circ}$ and $180^{\circ}$ over HOMO and LUMO are shown in Fig. S8. $\dagger$ Based on DFT energy, $\phi\left(50^{\circ}\right)$ conformation of DPIAPPB and CADPPI is more stable than $\phi\left(180^{\circ}\right)$ conformation; in HOMO, the electron density is located on TPA and $\mathrm{Cz}$ and in LOMO the electron density is localized on phenanthrimidazole moiety i.e., the HOMO and LUMO orbitals are separated from each other, therefore, CT transition of HOMO (TPA and Cz-donor) $\stackrel{\text { CT }}{\rightarrow}$ LUMO (phenanthrimidazole-acceptor) is possible. However, at $50^{\circ}$ (low energy twisting conformation), the electron density is partially localized on the Frontier orbitals of DPIAPPB and CADPPI. Therefore at $50^{\circ}, \mathrm{HOMO} \stackrel{\mathrm{CT}}{\rightarrow} \mathrm{LUMO}$ transition is not pure CT but it is intercrossed between CT and LE transitions. ${ }^{18}$ The HOMO and LUMO of DPIAPPB and CADPPI show separation however, differences are very small which enhanced the hole- and electron-transport properties (bipolar properties) and lowered the singlet-triplet splitting $\left(\Delta_{\mathrm{ST}}\right){ }^{58}$ The electron/hole transfer integrals of DPIAPPB $(0.29 / 0.33 \mathrm{eV})$ and CADPPI $(0.25 / 0.39 \mathrm{eV})$ supports their bipolar nature. ${ }^{59}$

The new born blue emitters show high quantum yield (solution/film) of DPIAPPB (0.82/0.70) and CADPPI (0.91/0.83) and the high fluorescence yield are essential for efficient blue OLEDs (Table 1). The higher quantum yield is due to the decreased proportion of non-radiative transition because of molecular interactions. ${ }^{60}$

Incorporation of anthracene into bulky phenanthrimidazole ring increased the steric hindrance and form more twisted structure in solid leads to lowered quantum yield in solid compared to solution due to less aggregation. However, the high solid-state quantum yield of these compounds benefit from the twisted architecture supports that these materials may employ as non-doped emitter layer in OLEDs. The highly rigid geometry of DPIAPPB and CADPPI effectively reduced the nonradiative exciton which results high yield. The $k_{\mathrm{r}} / k_{\mathrm{nr}}$ (radiative transition rate and non-radiative transition rate) have been calculated from lifetime $(\tau)$ and quantum yield $(\phi)$ (Table 1$)$. The relative contribution of radiative and non-radiative relaxation in the excited state deactivation was analyzed by radiative $\left(k_{\mathrm{r}}\right)$ and non-radiative $\left(k_{\mathrm{nr}}\right)$ decay constants: $k_{\mathrm{r}}=\tau / \Phi: 3.1 \mathrm{~s}^{-1}$ (DPIAPPB) and $3.6 \mathrm{~s}^{-1}$ (CADPPI); $k_{\mathrm{nr}}=\tau /(1-\Phi): 0.7 \mathrm{~s}^{-1}$ (DPIAPPB) and 0.3 $\mathrm{s}^{-1}$ CADPPI (Fig. $\mathrm{S} 2 \dagger$ ). The CADPPI shows larger radiative rate constant $\left(k_{\mathrm{r}}\right)$ and smaller non-radiative rate constant $\left(k_{\mathrm{nr}}\right)$ than DPIAPPB which results in enhanced $\eta_{\mathrm{PL}}$.

\subsection{HLCT character}

Their fluorescence spectra are broadened and gradually redshifted by increasing solvent polarity which indicates change of dipole moment between ground $\left(\mathrm{S}_{0}\right)$ and excited $\left(\mathrm{S}_{1}\right)$ states. The non-linear correlation of Lippert-Mataga plot supports the presence of two different excited states, locally excited state (LE) and charge transfer excited state (CT) in low and high polar solvents. The calculated ground state dipole $\left(\mu_{\mathrm{g}}\right)$ and excited state dipole $\left(\mu_{\mathrm{e}}\right)$ moments of DPIAPPB $\left(\mu_{\mathrm{g}}-4.67 \mathrm{D} ; \mu_{\mathrm{e}}-23.9 \mathrm{D}\right)$ and CADPPI $\left(\mu_{\mathrm{g}}-8.5 \mathrm{D} ; \mu_{\mathrm{e}}-24.1 \mathrm{D}\right)^{57}$ reveal that the large $\mu_{\mathrm{e}}$ in high polar medium is in close to $\mu_{\mathrm{e}}$ of 4 - $(N, N$-dimethylamino $)$ benzonitrile $(23.0 \mathrm{D}) .{ }^{61}$ The results are in close agreement with Ma et al., ${ }^{60}$ and confirmed both DPIAPPB and CADPPI show HLCT as single emissive state. The CT and LE dominates in more and less polar medium, respectively and there is mixed contribution of LE and CT in medium polar solvents. The coupling of LE with CT generates new HLCT emissive state. The HLCT state was confirmed by mono exponential time which supports the D- $-\mathrm{A}$ molecular design (Fig. S2 $\dagger$ ). ${ }^{62,63}$ The high oscillator strength of $\mathrm{S}_{1}$ state of CADPPI results in higher PL efficiency $\left(\eta_{\mathrm{PL}}\right)$. Molecular modification from TPA to $\mathrm{Cz}$ causes an increasing \% LE in $\mathrm{S}_{1}$ emissive state and enhanced $\eta_{\mathrm{PL}}$ of CADPPI. The overlap density between hole and particle depend upon the configuration of donor-acceptor architecture and the magnitude of overlap intensity tuned the \% LE and \% CT in $\mathrm{S}_{1}$ state (Fig. S9 $\dagger-$ CADPPI: Fig. S10 $\dagger-$ DPIAPPB). The twist angles $\left(\theta_{2}\right.$ and $\left.\theta_{3}\right)$ in $\mathrm{D}-\pi-\mathrm{A}$ linkage of CADPPI and DPIAPPB could be the origin for CT and LE intercross. In CADPPI and DPIAPPB, the $\mathrm{S}_{1}$ state remained unchanged with increasing solvent polarity whereas the $S_{3}$ state decreased to intercross with $S_{1}$ state at moderate polarity and to be much lower than $S_{1}$ state at high polarity. This reveals the HLCT as single emissive state. The LE and CT states of emissive materials DPIAPPB and CADPPI show non-uniform properties in different polar solvents because of different excited-state dipole moments. As the polarity increases, CT state is stabilized due to strong interaction of the solvent field with CT excited state (large dipole moment) and LE remains unchanged, ${ }^{64}$ however, in lowpolarity solvents, the LE being stabilized (low-lying excited state). ${ }^{56}$

The excited-state properties of CADPPI (Fig. S6†) and DPIAPPB (Fig. S7†) were analyzed using natural transition orbitals (NTOs) which show good balance between orbital overlap and spatial separation. ${ }^{65}$ The certain orbital overlaps exhibit local characters of their excited states. In the meanwhile, the existence of two components (CT and LE) is found by analyzing the calculated results which is in good agreement with the results of the HLCT states.

The electron density delocalization over hole and particles confirmed that in $\mathrm{S}_{0} \rightarrow \mathrm{S}_{1}$ transition, LE state dominates with minor contribution of CT state in HLCT and shows higher when 
compared with $\mathrm{S}_{0} \rightarrow \mathrm{S}_{2}$ or other $\mathrm{S}_{0} \rightarrow \mathrm{S}_{n}$ transitions $\left[f_{\mathrm{S}_{0} \rightarrow \mathrm{S}_{1}}=\right.$ $0.4041>f_{\mathrm{S}_{0} \rightarrow \mathrm{S}_{2}}=0.1644$ (DPIAPPB): $f_{\mathrm{S}_{0} \rightarrow \mathrm{S}_{1}}=0.5041>f_{\mathrm{S}_{0} \rightarrow \mathrm{S}_{2}}=$ 0.1882 (CADPPI)]. This is further evidence for higher \% LE in HLCT state and is highly need for efficient OLED performances. The eigen value $(>0.97)$ further supports the better mixed LE and CT excited state to about $87 \%$ of transition which is supported by $\Delta r>2$ for $\mathrm{S}_{1}-\mathrm{S}_{10}$ of CADPPI and DPIAPPB. The excitation energies of LE and CT states of the title materials were used as a tool to confirm the formation of HLCT state ${ }^{27}$ (Scheme $\mathrm{S} 1 \dagger$ ). In DPIAPPB and CADPPI, the LE state is stabilized than CT state due to enhanced $\pi$-conjugation. The overlap between hole and particle of CADPPI and DPIAPPB is displayed in Fig. S9 and $\mathrm{S} 10, \uparrow$ respectively. The more similar hole-electron wave function indicates the efficient hybridization between LE and CT states. The composition of HLCT in DPIAPPB (Fig. S9†) and CADPPI (Fig. S10†) can be analyzed by transition density matrix (TDM). The diagonal part reflects that the LE component localized on main backbone while off-diagonal region represents CT component. The atoms of CADPPI and DPIAPPB are labeled from acceptor (DPIAPPB \& CADPPI (1-47): phenanthrimidazole 1-25: spacer (anthracene) - 26-47) to donor carbazole (CADPPI 65-85) and triphenylamine (DPIAPPB48-80). The colored maps illustrate the matrix elements of the transitions from atoms on abscissa to atoms on ordinate for DPIAPPB and CADPPI. Since their atoms sequentially along the positive direction of each axes, the left-lower region represents LE transition, the right-lower region represents CT transition from donor (carbazole (CADPPI)/triphenylamine (DPIAPPB)) to PPI-An and the right-high region denotes LE transition, of donor. In this way, the LE: CT proportion of each structure could be directly calculated according to the calculus of matrix elements (Fig. S10 \& S11†).

\subsection{Quasi-equivalent hybridization}

The HONTOs and LUNTOs of $\mathrm{S}_{1}$ and $\mathrm{S}_{2}$ excited states of DPIAPPB and CADPPI exhibit a hybrid splitting character that derives from interstate coupling of LE and CT levels to form HLCT. The interstate hybridization coupling occurs through positive and negative linear combination between LE and CT state wave function: $\Psi_{\mathrm{S}_{1} / \mathrm{S}_{2}}=c_{\mathrm{LE}} \Psi_{\mathrm{LE}} \pm c_{\mathrm{CT}} \Psi_{\mathrm{CT}}$. The \% CT of
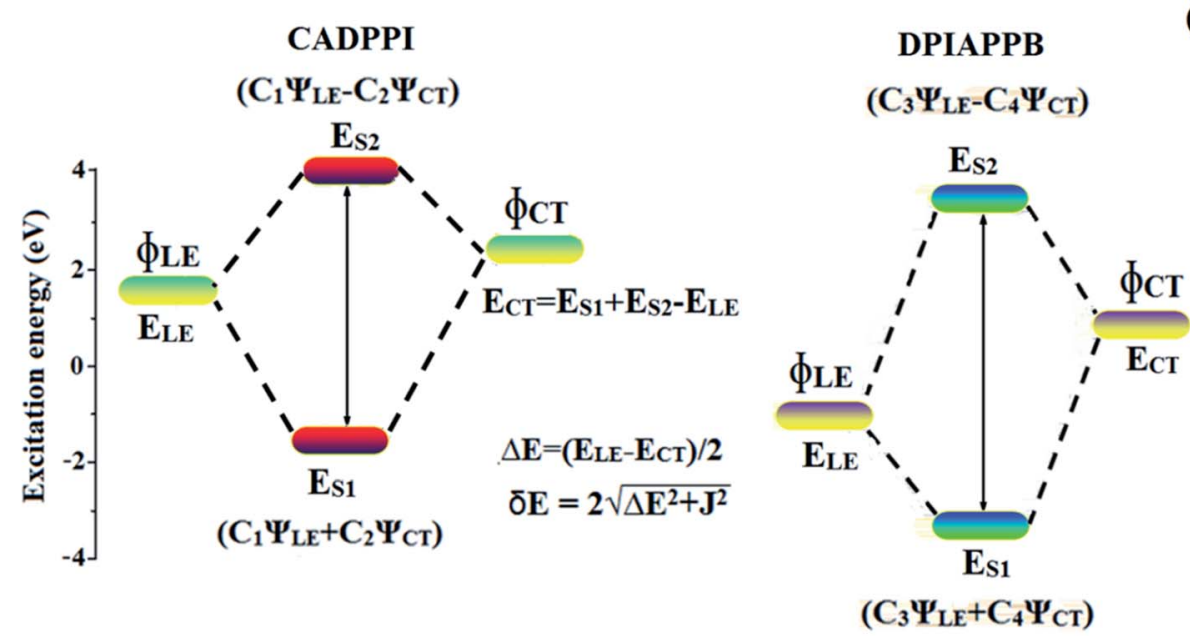

(a) 
CADPPI (65\%) is less than that of DPIAPPB (85\%) as a result of weak donor ability of $\mathrm{Cz}$ than TPA whereas high \% LE $(\sim 35 \%)$ in CADPPI than DPIAPPB ( 15\%) (Table 2$)$. A twisting D-A molecule $\quad N, N$-diphenyl-4-(7-phenylbenzo[ $c] 1,2,5$-thiadiazol-4-yl) aniline (TPA-BZP) exhibit special excited state character due to "hot exciton" with HLCT model, ${ }^{28}$ examined by solvatochromic experiment and quantum chemical calculation. The $\eta_{\mathrm{s}}$ of $42 \%$ was harvested from TPA-BZP based non-doped fluorescent OLED, breaking the $25 \%$ upper limit of spin statistics. ${ }^{4-6}$ However, the excessive CT component in $\mathrm{S}_{1}$ emissive state of TPA-BZP leads to lower the $\eta_{\mathrm{PL}}(49 \%$ - hexane and $40 \%$ - film). In order to maximize $\eta_{\mathrm{EQE}}$ of OLED, tuning the excited state is required to enhance $\eta_{\mathrm{PL}}$ in film i.e., to strengthen the LE component of $S_{1}$ state while maintaining $\eta_{\mathrm{s}}$ from hot exciton channel. Ma et al. ${ }^{60}$ reported that 4-(4-(9H-carbazol-9-yl)phenyl)7-phenylbenzo[ $c] 1,2,5$ thiadiazole (CzP-BZP) from a tiny chemical modification on TPA-BZP. Compared with TPABZP, the donor moiety triphenylamine (TPA) is replaced with weaker electron-donating carbazole-phenyl (CzP) in CzP-BZP, which is expected to decrease CT component as well as increase of LE component in $\mathrm{S}_{1}$ HLCT state of CzP-BZP. Thus, $\eta_{\mathrm{PL}}$ of CzP-BZP film is enhanced relative to TPA-BZP, with simultaneously high $\eta_{\mathrm{PL}}$ and high $\eta_{\mathrm{S}}\left[\eta_{\mathrm{PL}} / \eta_{\mathrm{S}}-75 \% / 48 \%\right.$ (CzP-BZP); $45 \% / 42 \%$ (TPABZP)] and leads to enhanced $\eta_{\mathrm{EQE}}$ in CzP-BZP $(6.95 \%)$ than TPA-BZP (3.80\%) OLED and to validate the HLCT and "hot exciton" mechanism.

As a result, CADPPI exhibits higher photoluminescence efficiency $\left(\eta_{\mathrm{PL}}\right)$ and blue shifted emission relative to DPIAPPB. The $S_{1}$ and $S_{2}$ excited states of DPIAPPB and CADPPI are similar in energy, oscillator strength and HONTOs and LUNTOs distribution indicates a quasi-equivalent hybridization between LE and CT states due to their almost iso-energetic initial states. Compared with solvatochromic effect, the formation and dissociation processes of the HLCT state are clarified together with its influencing factors. The excited state hybridizing process can be treated as exciton coupling proposed by Lambert et $a .^{66}$

$$
\delta E=2 \sqrt{\Delta E^{2}+J^{2}}: \Delta E=\left(E_{\mathrm{LE}}-E_{\mathrm{CT}}\right) / 2\left(E_{\mathrm{LE}}>E_{\mathrm{CT}}\right)
$$

where, $\delta E$ is energy splitting between $\mathrm{S}_{1}$ and $\mathrm{S}_{2}$ states of CADPPI and DPIAPPB and $2 \Delta E$ is energy difference between two initial pure states $\Psi(\mathrm{CT})$ and $\Psi(\mathrm{LE})$ before their interaction occurs. Using exciton coupling model, we can estimate the exciton coupling $J$ between $\varphi(\mathrm{CT})$ and $\varphi(\mathrm{LE})$ excitons. (i) The excitation energies of the first ten singlet states can be calculated. (ii) Once the excitation energies $\left(E_{\mathrm{LE}}\right)$ of the pure LE state and two hybridized states $\left(\mathrm{S}_{1}\right.$ and $\left.\mathrm{S}_{2}\right)$ are obtained in CADPPI and DPIAPPB, the excitation energies of pure CT states $\left(E_{\mathrm{CT}}\right)$ according to the energy conservation $\left(E_{\mathrm{S}_{1}}+E_{\mathrm{S}_{2}}=E_{\mathrm{LE}}+E_{\mathrm{CT}}\right)$ can be calculated as well as the energy gaps $\left(2 \Delta E=E_{\mathrm{LE}}-E_{\mathrm{CT}}\right)$ between pure LE and pure CT states also calculated (Fig. 3). In both CADPPI and DPIAPPB the LE state stabilizes in energy due to enhanced $\pi$-conjugation while the CT state destabilizes remarkably leading to greatly reduced energy gap between LE and CT states $(2 \Delta E)$ and the interstate coupling $(J)$ becomes high. Thus, both LE and CT states can be fully hybridized into $\mathrm{S}_{1}$ and $\mathrm{S}_{2}$ states which are close to the quasi-equivalent hybridization as a result of reduced energy gap. For nonequivalent
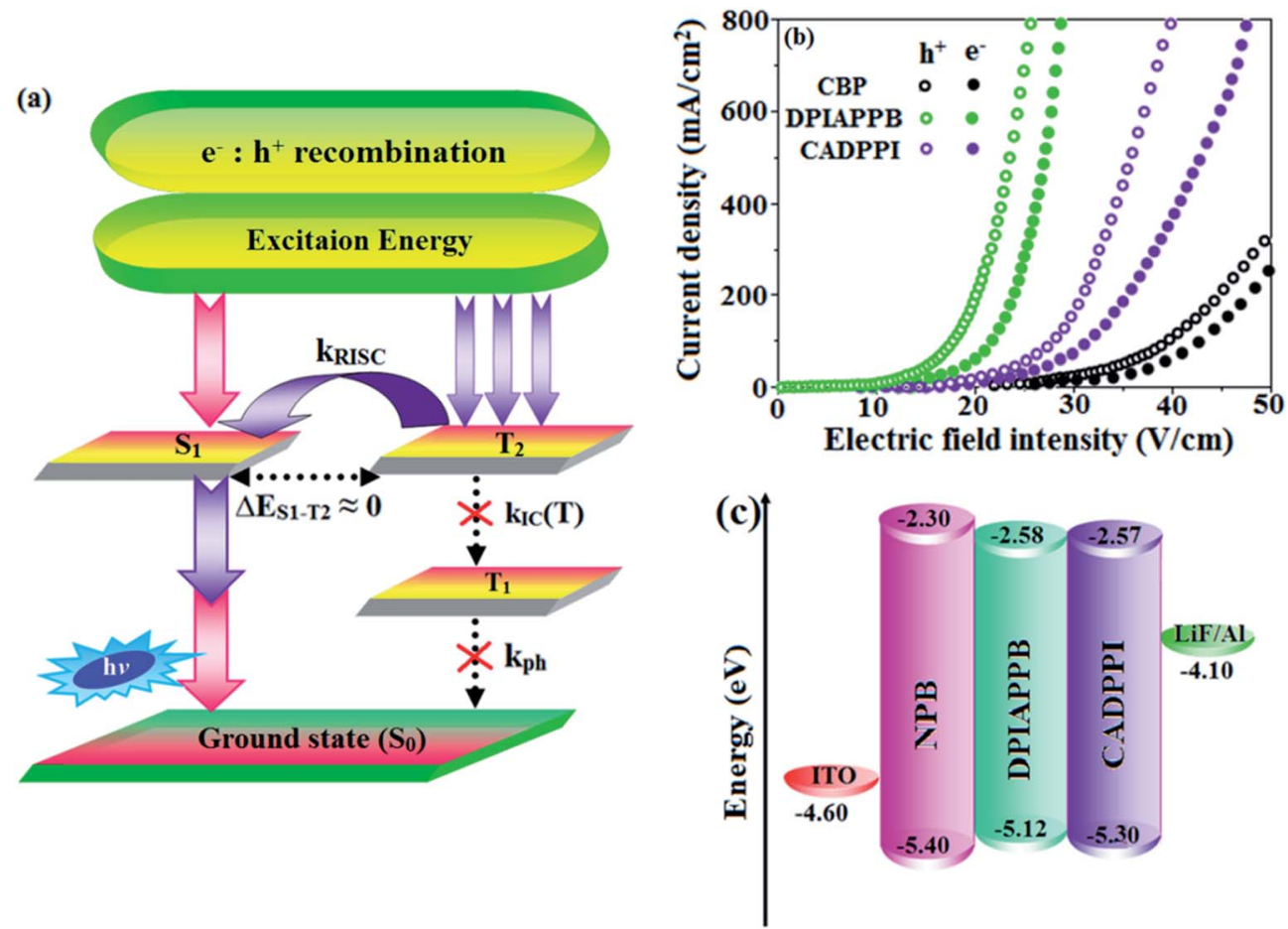

Fig. 4 (a) Scheme of exciton decay process after hole and electron recombination in OLEDs of D- $\Pi-A$ molecules; (b) hole-only and electrononly devices based on CADPPI and DPIAPPB; (c) energy level diagram of non-doped devices. 
hybridization, the $S_{1}$ and $S_{2}$ excited states have difference in energy, oscillator strength and HONTOs and LUNTOs image due to non-equivalent hybridization between LE and CT initial states. ${ }^{67}$ Therefore, degree of hybridization between LE and CT states depends not only initial $E_{\mathrm{LE}}-E_{\mathrm{CT}}$ energy gap but also their interstate coupling strength. ${ }^{68}$

Compared with non-equivalent hybridization, quasiequivalent hybridization is expected to achieve the combination of high $\eta_{\mathrm{PL}}$ and high $\eta_{\mathrm{S}}$ to maximize EL efficiency of fluorescent OLED materials due to more balanced LE and CT components in HLCT state of DPIAPPB and CADPPI. In DPIAPPB and CADPPI, the LE state is stabilized than CT state and energy gap $\left(E_{\mathrm{S}_{2}}-E_{\mathrm{S}_{1}}\right)$ is small when compared to parent compounds results quasi hybridization. The energy gap $\left(E_{\mathrm{S}_{2}}\right.$ $\left.E_{\mathrm{S} 1}\right)$ of CADPPI is reduced more when compared with DPIAPPB results effective hybridization and improves OLED efficiency. The qualitatively calculated percentage of LE and CT in $S_{1}-S_{10}$ and $\mathrm{T}_{1}-\mathrm{T}_{10}$ states are displayed in Table 2 . This also supports that HLCT state also contributes to hybridization apart from LE and CT states. However, the more balanced LE and CT components in HLCT state of DPIAPPB and CADPPI enhanced the EL efficiency. The formation of HLCT state can be analyzed through the excitation energies of LE and CT states. For "hot exciton" process, their low-lying triplet excited state $\left(\mathrm{T}_{1}\right)$ and second-lying triplet excited state $\left(\mathrm{T}_{2}\right)$ was calculated.

Interestingly, a similar electron density is found between high-lying triplet excited state $\mathrm{T}_{2}$ (CT state for CADPPI and DPIAPPB) and HLCT $\mathrm{S}_{1}$ state. In Fig. 3 , the calculated $E_{\mathrm{S}_{1}}$ (0.9499 eV for CADPPI and $0.7395 \mathrm{eV}$ for DPIAPPB) and $E_{\mathrm{T}_{2}}$ (0.9498 eV for CADPPI and $0.7395 \mathrm{eV}$ for DPIAPPB) are almost same. A small singlet-triplet splitting $\left(\Delta E_{\mathrm{ST}}\right)$ supports the potential reverse intersystem crossing (RISC) from $\mathrm{T}_{2} \stackrel{\text { RISC }}{\longrightarrow} S_{1}$. The large energy gap between $\mathrm{T}_{2}$ and $\mathrm{T}_{1}$ states CADPPI $(0.74 \mathrm{eV})$ and DPIAPPB $(0.53 \mathrm{eV})$ reflect internal conversion from $\mathrm{T}_{2} \stackrel{\mathrm{IC}}{\rightarrow} \mathrm{T}_{1}$ states is smaller than RISC from $T_{2}$ to $S_{1}$. A large energy gap between $\mathrm{T}_{1}$ and $\mathrm{T}_{2}$ of CADPPI $(0.74 \mathrm{eV})$ and DPIAPPB $(0.53 \mathrm{eV})$ arising from the same phenanthrimidazole acceptor and the energy gap between $\mathrm{T}_{1}$ and $\mathrm{T}_{2}$ of CADPPI is larger than DPIAPPB
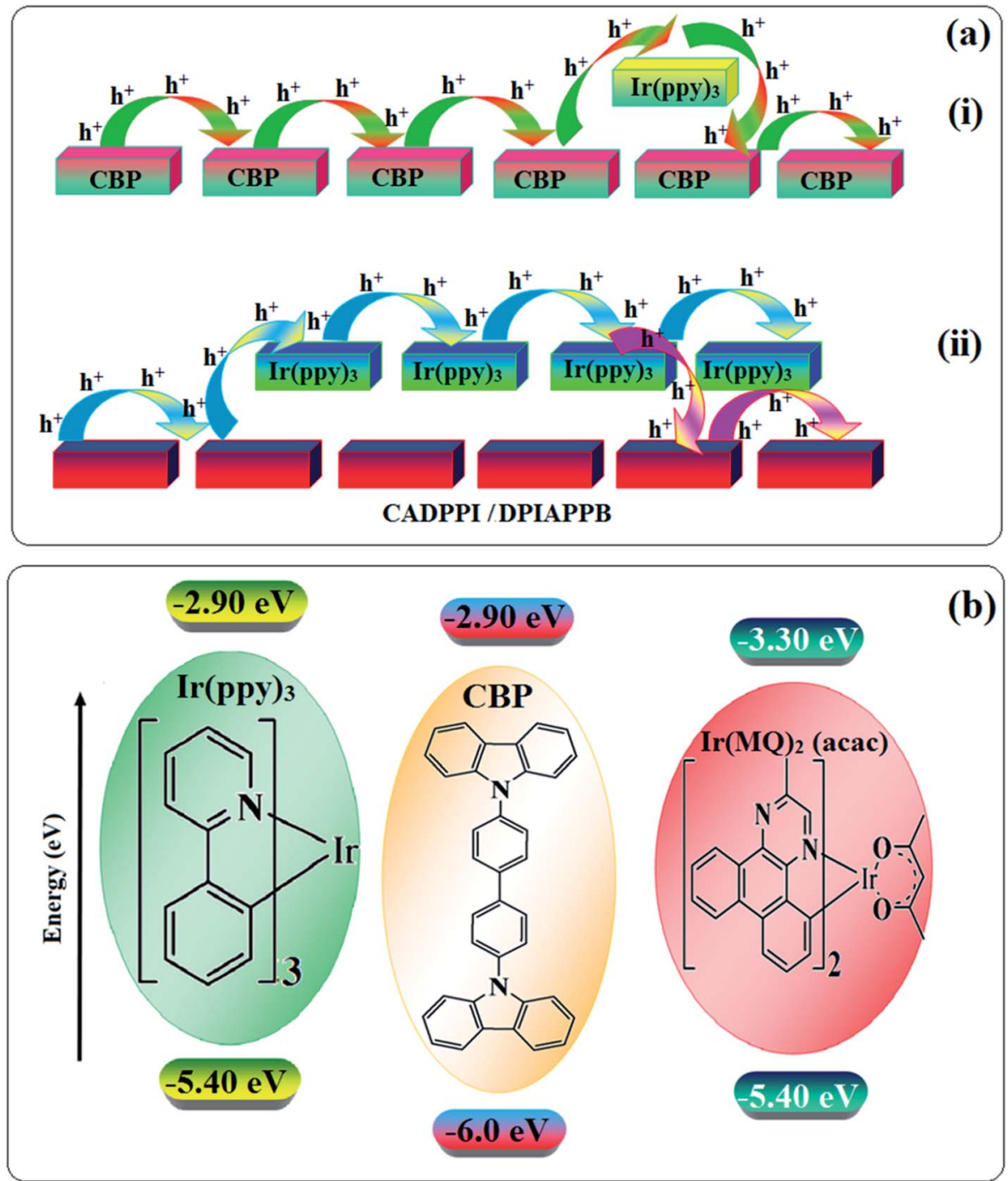

Fig. 5 (a) Schematic representation of (i) carrier trapping at Ir(ppy) 3 and (ii) carrier hopping through both $\operatorname{Ir}($ ppy) 3 and CADPPI and DPIAPPB and (b) HOMO-LUMO energy levels of green and red phosphorescent materials. 
(Fig. 3) ${ }^{69,70}$ A very small $\Delta E_{\mathrm{ST}} \approx 0$ is observed between $\mathrm{S}_{1}$ and $\mathrm{T}_{2}$ states facilitating RISC $\left(\mathrm{T}_{2} \rightarrow \mathrm{S}_{1}\right)$ process as a result of their HLCT character.

Excited state characters play a key role in PL and electroluminescence (EL) properties of OLEDs. Charge-transfer state is beneficial to enhance the singlet exciton utilization $\left(\eta_{\mathrm{s}}\right)$ in fluorescent OLEDs by RISC due to small singlet and triplet energy splitting $\left(\Delta E_{\mathrm{ST}}\right)$ in CT exciton. However, the dominant CT component in the emissive state reduces the PL efficiency in such materials. Here, the strategy is to carry out for fine excited state modulation to achieve the combined effect of high $\eta_{\mathrm{PL}}$ using LE component and high $\eta_{\mathrm{s}}$ utilizing CT component in single emissive HLCT state. As a result, a quasi-equivalent hybridization of LE and CT components obtained in the emissive state upon addition of anthracene bridge in the newly synthesized material.

\subsection{Single carrier devices}

To understand the hole and electron transport abilities of DPIAPPB and CADPPI, hole-only device (HOD) and electrononly device (EOD) have been fabricated with a structure of ITO/NPB (8 nm)/DPIAPPB/CADPPI (50 nm)/NPB (8 nm)/LiF (1 $\mathrm{nm}) / \mathrm{Al}(100 \mathrm{~nm})$ (Hole-only device) and ITO/TPBi $(8 \mathrm{~nm}) /$ DPIAPPB/CADPPI $(40 \mathrm{~nm}) / \mathrm{TPBi}(8 \mathrm{~nm}) / \mathrm{Al}(100 \mathrm{~nm})$ (Electrononly device). Fig. 4 shows the current density versus voltage characteristics of hole-only and electron-only devices. The electron current density of DPIAPPB and CADPPI based device is higher than CBP-based device which reveal that these DPIAPPB and CADPPI compounds are bipolar-transporting materials with effectively transporting both electrons and holes than CBP. ${ }^{71-73}$

In CBP: $5 \mathrm{wt} \% \operatorname{Ir}(\mathrm{ppy})_{3}$ device the carrier current decreases significantly since the carrier may undergo deep trapping at the HOMO level of $\operatorname{Ir}(\mathrm{ppy})_{3}$. However, in DPIAPPB (30 nm): $5 \mathrm{wt} \%$ $\operatorname{Ir}(\text { ppy })_{3}$ or CADPPI $(30 \mathrm{~nm}): 5 \mathrm{wt} \% \operatorname{Ir}(\text { ppy })_{3}$ based devices, the carrier current increased which may be attributed to the effect of direct injection into the dopant HOMO levels and the hopping transport thorough both CADPPI and DPIAPPB dopant sites (Fig. 5).

\subsection{Electroluminescent studies}

The effective film forming properties of emissive materials are important for device efficiency. The better nanoscale morphology of annealed DPIAPPB and CADPPI thin film (Fig. 6) is attributed to low turn-on voltage. Energy-level diagram of the materials used for the fabrication of devices are shown in Fig. 4. The TADF materials will show flat decay curve due to the time consuming TADF process for the exciton conversion from triplet to singlet, however, the observed single-exponential sharp decay of DPIAPPB and CADPPI shows that the radiative exciton are short-lived component without TADF contribution (Fig. S2†).
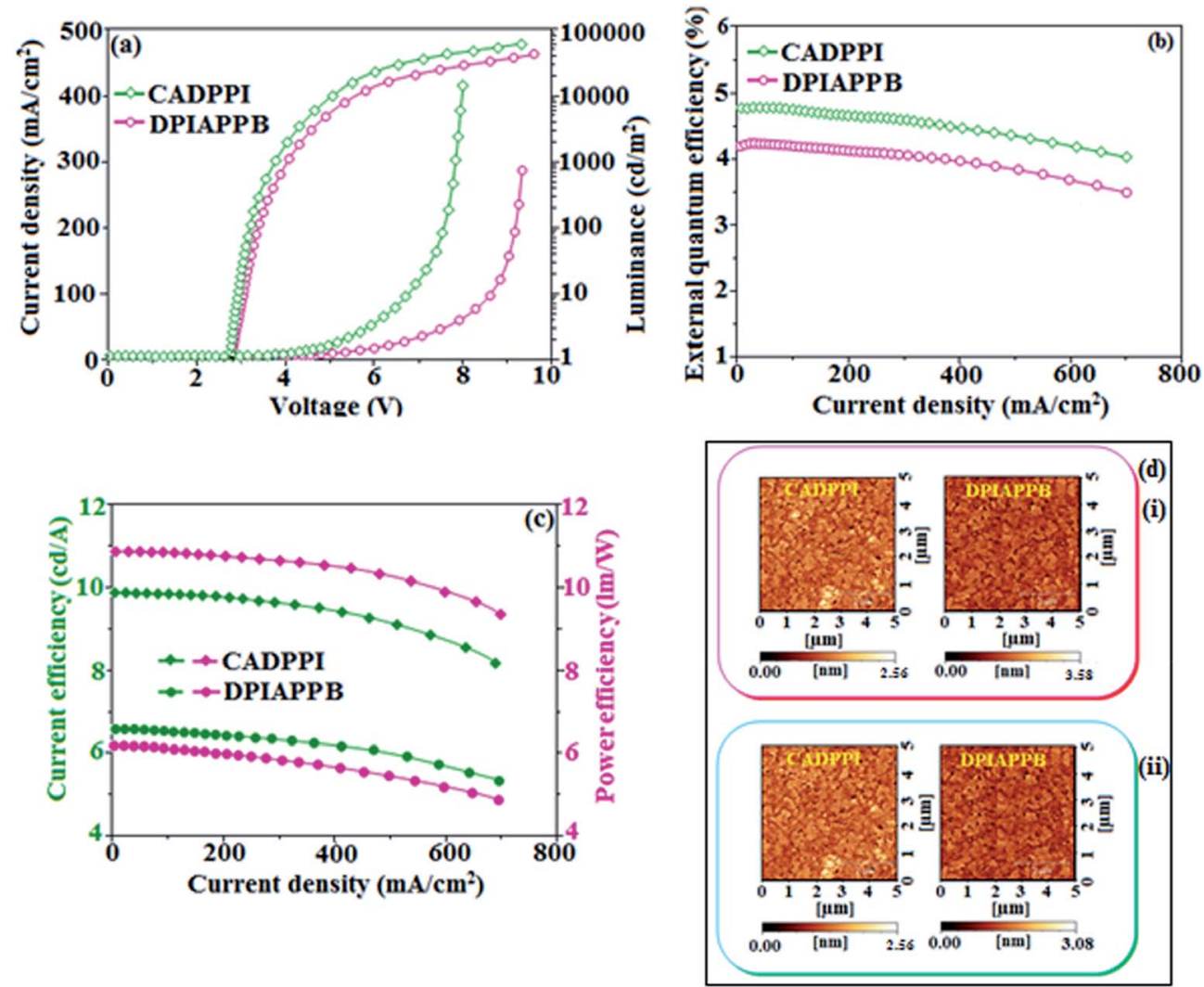

Fig. 6 Device efficiencies: (a) luminance-voltage; (b) external quantum efficiency-current density; (c) current efficiency/power efficiencycurrent density and (d) AFM images (at room temperature (i) and after annealing at $90{ }^{\circ} \mathrm{C}$ (ii)) of CADPPI and DPIAPPB. 
The mono-exponential lifetime measurement reveal that this intercrossed excited state in moderate polar solvents should be a HLCT instead of two species state through a addition of LE and CT which also supports the molecular design (Scheme S1 $\dagger$ ). Therefore, the exciton utilization efficiency $\left(\eta_{\mathrm{S}}\right)$ in DPIAPPB and CADPPI are of neither TTA nor TADF mechanism.

The vacuum processed blue OLEDs with configuration of ITO/NPB (60 nm)/DPIAPPB/CADPPI (20 nm)/LiF (1 nm)/Al (100 $\mathrm{nm}$ ) have been fabricated (Fig. 4). The electroluminescence (EL) spectra of the devices are similar to their PL spectra which shows both EL and PL originates from the same radiative decay of the singlet exciton. High device performances at low-turn on voltage are extracted from non-doped devices based on DPIAPPB and CADPPI (Fig. 6; Table 1). The CADPPI based device (EL - $467 \mathrm{~nm})$ shows high efficiencies $\left(\eta_{\mathrm{c}}-9.85 \mathrm{~cd} \mathrm{~A}^{-1} ; \eta_{\mathrm{p}}\right.$ - $\left.10.84 \mathrm{~lm} \mathrm{~W}^{-1} ; \eta_{\mathrm{ex}}-4.78 \%\right)$ at $2.8 \mathrm{~V}$ with $\mathrm{CIE}(0.15,0.10)$ compared to DPIAPPB device (EL $-472 \mathrm{~nm})\left(\eta_{\mathrm{c}}-6.56 \mathrm{~cd} \mathrm{~A}^{-1} ; \eta_{\mathrm{p}}\right.$ $\left.-6.16 \mathrm{~lm} \mathrm{~W}^{-1} ; \eta_{\mathrm{ex}}-4.15 \%\right)$ at $2.8 \mathrm{~V}$ with $\operatorname{CIE}(0.15,0.12)$. The high $\eta_{\mathrm{ex}}$ harvested from CADPPI and DPIAPPB based device is due to the co-emission from intercrossed excited state of LE and
$\mathrm{CT}$; the isoenergies of singlet $\left({ }^{1} \mathrm{CT}\right)$ and triplet $\left({ }^{3} \mathrm{CT}\right)$ make ${ }^{3} \mathrm{CT}$ $\rightarrow{ }^{1} \mathrm{CT}$ transition as spin-allowed transition. ${ }^{74}$ The inevitable vibration splitting in the strongly rigid phenanthro-9,10- $d$ imidazole structure of DPIAPPB and CADPPI may be enhanced in OLEDs to show large full peak width with red-shifted CIE. Actually, the quantum yield of CADPPI and DPIAPPB films are 83.0\% and $70.0 \%$, respectively. Thus, the upper limit of EQE calculated from the following equation: $\mathrm{EQE}=\eta_{\text {out }} \times \eta_{\mathrm{rc}} \times \eta_{\gamma}$ $\times \Phi_{\mathrm{PL}} \cdot{ }^{75,76}$ Using the quantum yield of CADPPI $(83.0 \%)$ and DPIAPPB (70.0\%) the calculated theoretical maximum EQE are of $4.15 \%$ and $3.50 \%$. While the experiment EQE are of $4.78 \%$ and $4.15 \%$, respectively. The $\eta_{\mathrm{r}}$ calculated for DPIAPPB (40$50 \%$ ) and CADPPI (29-36\%) indicates $\gamma$ is less than $100 \%$ due to very small unbalanced carrier transportation. ${ }^{77}$ This result could be attributed more balanced charge-transporting properties within the emissive layer achieved by better charge injection provided by hole transport layer. The $\eta_{\mathrm{IQE}}$ can be calculated from $\eta_{\mathrm{EQE}} \div \eta_{\text {out }}$ as DPIAPPB (20.1\%) and CADPPI (23\%) and maximum $\eta_{\mathrm{s}}$ of DPIAPPB (35.1\%) and CADPPI $(42.9 \%)$ of EL devices can be estimated using the equation, $\eta_{\mathrm{s}}=$

Table 3 Summary of device efficiencies with reported non-doped emitters

\begin{tabular}{|c|c|c|c|c|c|c|c|}
\hline Emitter & $V_{\text {on }}(\mathrm{V})$ & $L\left(\mathrm{~cd} \mathrm{~m}^{-2}\right)$ & $\mathrm{EL}(\mathrm{nm})$ & $\eta_{\mathrm{c}}\left(\mathrm{cd} \mathrm{\textrm {A } ^ { - 1 }}\right)$ & $\eta_{\mathrm{p}}\left(\operatorname{lm} \mathrm{W}^{-1}\right)$ & $\operatorname{CIE}(x, y)$ & Ref. \\
\hline CADPPI & 2.3 & 52823 & 467 & 9.85 & 10.84 & $(0.15,0.10)$ & This work \\
\hline DPIAPPB & 2.3 & 38625 & 472 & 6.56 & 6.16 & $(0.15,0.12)$ & This work \\
\hline Cz-DPVI & 3.4 & 13629 & 419 & 4.9 & 4.3 & $(0.15,0.08)$ & 67 \\
\hline Cz-DMPVI & 3.2 & 13841 & 430 & 5.4 & 5.0 & $(0.15,0.08)$ & 67 \\
\hline Cz-DEPVI & 2.8 & 13955 & 439 & 6.0 & 5.4 & $(0.15,0.08)$ & 67 \\
\hline TPA-DEPVI & 2.9 & 13856 & 442 & 5.7 & 5.2 & $(0.15,0.07)$ & 67 \\
\hline PPI & 3.8 & 3307 & 412 & 0.71 & 0.40 & $(0.161,0.065)$ & 79 \\
\hline mTPA-PPI & 3.2 & 4065 & 404 & 0.84 & 0.48 & $(0.161,0.049)$ & 79 \\
\hline L-BPPI (50 nm) & 8.5 & 70 & 440 & 0.01 & - & $(0.16,0.11)$ & 80 \\
\hline L-BPPI (40 nm) & 6.5 & 295 & 440 & 0.13 & - & $(0.16,0.11)$ & 80 \\
\hline L-BPPI (30 nm) & 5.0 & 420 & 440 & 0.40 & - & $(0.16,0.10)$ & 80 \\
\hline L-BPPI (20 nm) & 4.5 & 391 & 440 & 0.68 & - & $(0.16,0.10)$ & 80 \\
\hline Z-BPPI (50 nm) & 6.5 & 105 & 440 & 0.07 & - & $(0.17,0.12)$ & 80 \\
\hline Z-BPPI (40 nm) & 5.0 & 502 & 440 & 0.34 & - & $(0.16,0.12)$ & 80 \\
\hline Z-BPPI (30 nm) & 4.5 & 267 & 440 & 0.45 & - & $(0.16,0.12)$ & 80 \\
\hline Z-BPPI (20 nm) & 5.0 & 100 & 440 & 0.31 & - & $(0.16,0.11)$ & 80 \\
\hline CPBPMCN (HTL-40P + $10 \mathrm{~nm})$ & 3.4 & $10{ }^{80} 0$ & - & 3.11 & 2.21 & $(0.15,0.08)$ & 78 \\
\hline CPBPMCN (HTL-20P + $40 \mathrm{~nm})$ & 3.8 & 9755 & - & 3.82 & 2.86 & $(0.15,0.08)$ & 78 \\
\hline TPA-PIM & - & 4510 & 420 & 1.14 & 0.79 & $(0.161,0.046)$ & 78 \\
\hline TPA-An & & 24910 & 468 & 4.54 & 4.02 & $(0.15,0.19)$ & 81 \\
\hline TPA-PA & & 11970 & 428 & 4.07 & 3.36 & $(0.157,0.073)$ & 81 \\
\hline Py-BPI (bilayer-BPhen) & 3.4 & - & 468 & 3.93 & 3.2 & $(0.15,0.20)$ & 82 \\
\hline Py-BPI (bilayer-TPBi) & 3.2 & - & 468 & 2.03 & 1.00 & $(0.15,0.15)$ & 82 \\
\hline PhBPI & 2.8 & - & 450 & 1.87 & 1.85 & - & 83 \\
\hline MADN & 3.2 & - & - & 2.00 & 0.7 & $(0.15,0.10)$ & 84 \\
\hline TPA-BPI & 4.7 & - & 448 & 1.83 & 1.58 & $(0.15,0.09)$ & 85 \\
\hline BPA-BPI & 3.6 & & 428 & 3.6 & 0.55 & $(0.15,0.05)$ & 85 \\
\hline PATPA & 5.3 & & 424 & 0.34 & 0.20 & $(0.15,0.06)$ & 85 \\
\hline TPA-TPI & 4.4 & & 496 & 4.0 & 2.8 & $(0.18,0.40)$ & 85 \\
\hline DPVBi & 7.5 & - & 457 & 0.03 & - & $(0.15,0.13)$ & 86 \\
\hline DPVICz & 4.2 & - & 470 & 0.92 & - & $(0.15,0.22)$ & 86 \\
\hline DPVTCz & 3.8 & - & 470 & 1.94 & - & $(0.14,0.22)$ & 86 \\
\hline 3,6-DPVTCz & 5.0 & - & 449 & 0.11 & - & $(0.15,0.11)$ & 86 \\
\hline 3 & 4.0 & 2800 & 460 & 0.61 & 0.14 & $(0.15,0.14)$ & 87 \\
\hline 4 & 3 & 10600 & 407 & 1.68 & 1.10 & $(0.16,0.13)$ & 87 \\
\hline 5 & 2.5 & 21200 & 392 & 1.90 & 1.55 & $(0.16,0.14)$ & 87 \\
\hline
\end{tabular}


$\eta_{\text {res }} \times \eta_{\mathrm{PL}} \times \eta_{\text {out }} \div \eta_{\mathrm{EL}}$, The enhanced $\eta_{\mathrm{s}}$ and $\eta_{\mathrm{IQE}}$ is probably due to the maintained CT component of D-П-A compounds. The maximum $\eta_{\mathrm{s}}$ of DPIAPPB (35.1\%) and CADPPI (42.9\%) was breaking through the limit of $25 \%$ according to spin statistics, these two molecules exhibit light emitting mechanism as HLCT (Fig. 3): $10.1 \%$ of triplet translate to singlet excitons by reverse intersystem crossing progress to enhance the fluorescence emission and the rest lie away through non-radiative progress for DPIAPPB. As for CADPPI, there are $17.9 \%$ of the triplet excitons translating to singlet excitons. This provides the possibility of high efficiency blue OLEDs. The device efficiencies are compared with already reported non-doped emitters efficiencies $^{67,78-87}$ (Table 3; Fig. S12†) which shows that the newly synthesized non-doped devices based on DPIAPPB and CADPPI are the best in terms of efficiencies. These experimental results demonstrated that the additional triplet exciton have been utilized in the OLED applications for the HLCT character of DPIAPPB and CADPPI as shown in Scheme S1† and showing the accuracy for our molecular design strategy. Devices with DPIAPPB and CADPPI show maximum luminance $(L)$ of 38625 and $52823 \mathrm{~cd} \mathrm{~m}^{-2}$, respectively. The EL brightness has a linear relationship with current density for these compounds indicating that the contribution from triplet-triplet annihilation was insignificant. ${ }^{88}$ The emission wavelength of DPIAPPB and CADPPI in film is close to that in ethyl ether which supports the HLCT state formed in DPIAPPB and CADPPI film.

The calculated triplet energy $\left(E_{\mathrm{T}}\right)$ of DPIAPPB $(2.48 \mathrm{eV})$ and CADPPI $(2.57 \mathrm{eV})$ shows that they have high triplet energy to sensitize phosphorescent dopants with $E_{\mathrm{T}}$ below $2.3 \mathrm{eV}$. These DPIAPPB and CADPPI are also employed as host materials for green and red phosphorescent dopants. The vacuum processed green and red devices are with configuration of ITO/NPB (40 $\mathrm{nm}) /$ TCTA $(5 \mathrm{~nm}) /$ DPIAPPB $(30 \mathrm{~nm}): 5 \mathrm{wt} \% \operatorname{Ir}(\mathrm{ppy})_{3}$ or CADPPI (30 nm): 5 wt $\% \operatorname{Ir}(\text { ppy })_{3} /$ TPBi $\left.(50 \mathrm{~nm}) / \mathrm{LiF}(1 \mathrm{~nm}) / \mathrm{Al}(100 \mathrm{~nm})\right]$ : ITO/NPB (40 nm)/TCTA (5 nm)/DPIAPPB (30 nm): 8 wt\% $\operatorname{Ir}(\mathrm{MDQ})_{2}(\mathrm{acac})$ or CADPPI $(30 \mathrm{~nm}): 8 \mathrm{wt} \% \operatorname{Ir}(\mathrm{MDQ})_{2}(\mathrm{acac}) / \mathrm{TPBi}$ $(50 \mathrm{~nm}) / \mathrm{LiF}(1 \mathrm{~nm}) / \mathrm{Al}(100 \mathrm{~nm})]$, respectively have been fabricated (Fig. 7). The device performances are shown in Fig. 8. The EL spectra are similar to PL spectra of the doped thin film (Fig. 2). The green device (432 nm) with CADPPI (30 nm): $5 \mathrm{wt} \%$

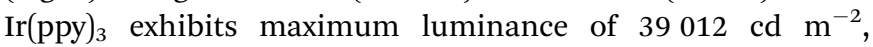
maximum current and power efficiencies are of $80.1 \mathrm{~cd} \mathrm{~A}^{-1}$ and $87.3 \mathrm{~lm} \mathrm{~W}^{-1}$, respectively, at $2.6 \mathrm{~V}$ with CIE $(0.27,0.62)$ (Table 4$)$. The maximum external quantum efficiencies of the devices based on CADPPI:Ir(ppy $)_{3}$ and DPIAPPB: $\operatorname{Ir}(\text { ppy })_{3}\left[\eta_{\mathrm{c}}-76.2 \mathrm{~cd}\right.$ $\mathrm{A}^{-1} ; \eta_{\mathrm{p}}-86.5 \mathrm{~lm} \mathrm{~W} \mathrm{~W}^{-1} ; L-38765 \mathrm{~cd} \mathrm{~m}^{-2}$; CIE $\left.(0.27,0.62)\right]$ are of 23.0 and $22.1 \%$, respectively. Similar to green device, red device $(630 \mathrm{~nm})$ with CADPPI: $\operatorname{Ir}(\mathrm{MDQ})_{2}$ (acac) exhibits maximum luminance of $30456 \mathrm{~cd} \mathrm{~m}^{-2}$ and excellent EL efficiencies $\left(\eta_{\mathrm{ex}}-\right.$ $\left.21.9 \% ; \eta_{\mathrm{c}}-26.0 \mathrm{~cd} \mathrm{~A}{ }^{-1} ; \eta_{\mathrm{p}}-26.2 \mathrm{~lm} \mathrm{~W}^{-1}\right)$ with CIE $(0.64,0.35)$ compared to DPIAPPB: $\operatorname{Ir}(\mathrm{MDQ})_{2}$ (acac) based device $(L-31068$

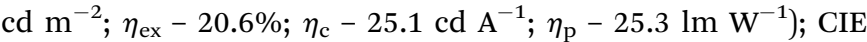
$(0.64,0.35)$ with EL $636 \mathrm{~nm}$. The fabricated green and red device efficiencies are compared with reference green device CBP: $\operatorname{Ir}(\text { ppy })_{3}\left(L-33128 \mathrm{~cd} \mathrm{~m}^{-2} ; \eta_{\mathrm{ex}}-12.3 \% ; \eta_{\mathrm{c}}-26.2 \mathrm{~cd} \mathrm{~A}^{-1} ; \eta_{\mathrm{p}}\right.$ $\left.-26.7 \mathrm{~lm} \mathrm{~W}^{-1}\right)$ and red device- CBP: $\operatorname{Ir}(\mathrm{MQ})_{2}$ (acac) $(L-30568 \mathrm{~cd}$ $\left.\mathrm{m}^{-2} ; \eta_{\mathrm{ex}}-10.8 \% ; \eta_{\mathrm{c}}-22.0 \mathrm{~cd} \mathrm{~A}^{-1} ; \eta_{\mathrm{p}}-22.4 \mathrm{~lm} \mathrm{~W}^{-1}\right)$. The above experimental results demonstrate that CADPPI and DPIAPPB are universal host materials for green and red phosphorescent emitters (Table 4).
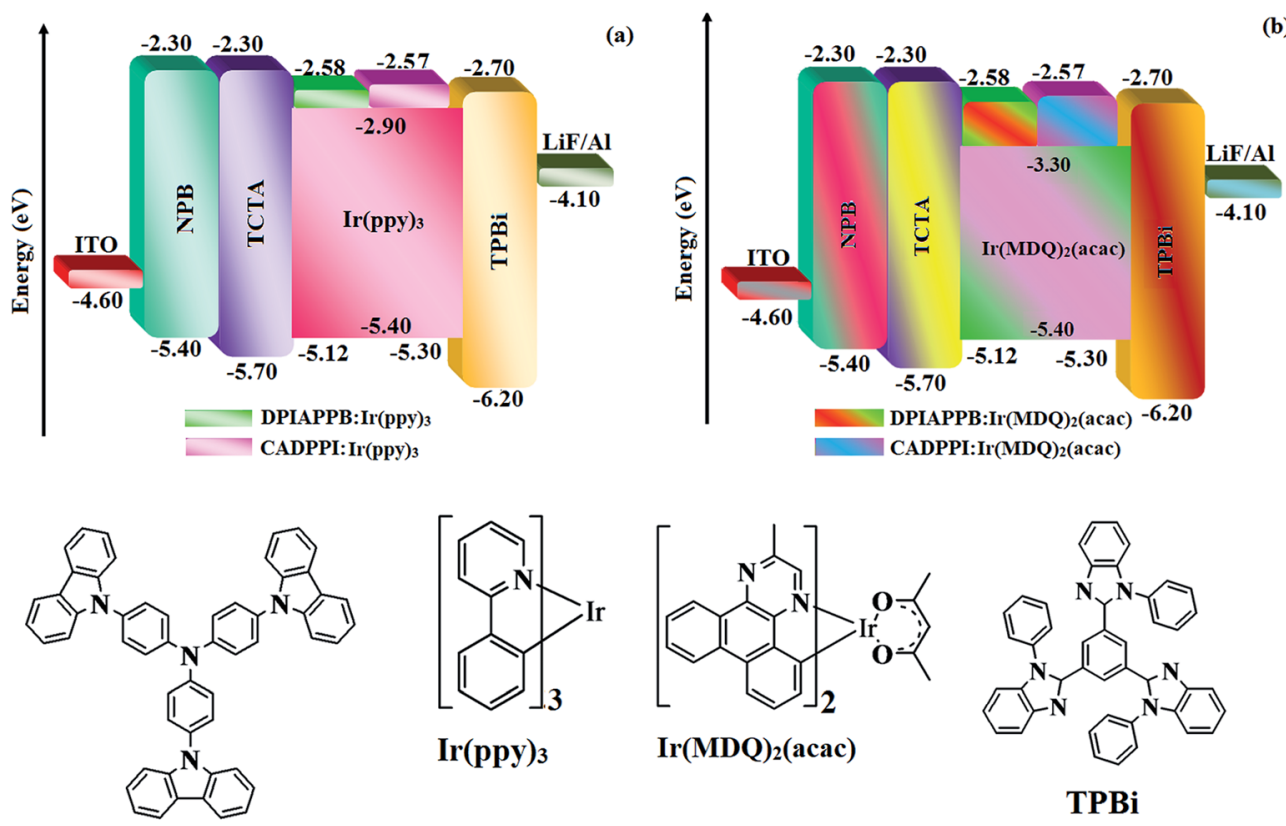

$\operatorname{Ir}($ ppy) 3
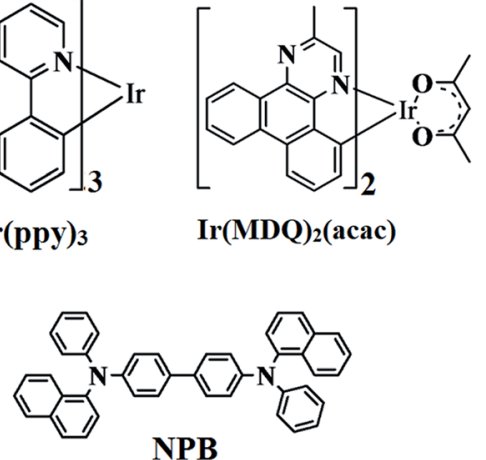

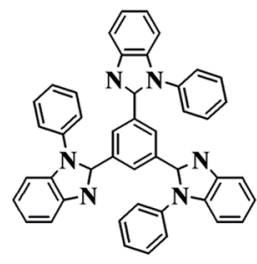

TPBi

TCTA

Fig. 7 Energy level diagram of green (a) and red (b) devices with molecular structures of functional materials. 

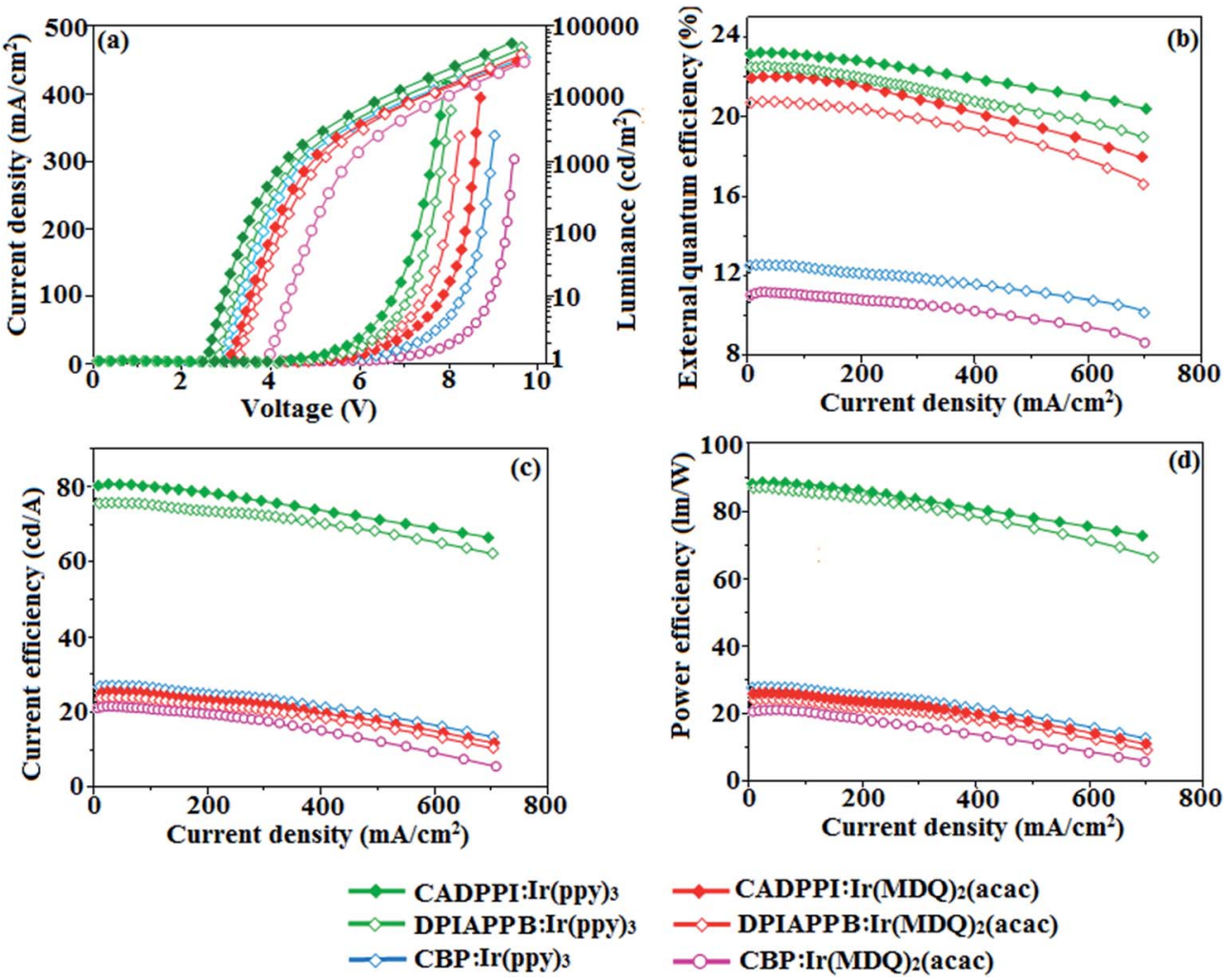

Fig. 8 Device efficiencies: (a) luminance-voltage; (b) external quantum efficiency-current density; (c) current efficiency-current density and (d) power efficiency-current density of CADPPI, DPIAPPB and green devices based on CADPPI:Ir(ppy) ${ }_{3}$, DPIAPPB:Ir(ppy) 3 , and red devices with CADPPI:Ir(MDQ) ${ }_{2}$ (acac) and DPIAPPB:Ir(MDQ) ${ }_{2}($ acac)

Table 4 Optoelectric efficiencies of various PHOLED devices

\begin{tabular}{|c|c|c|c|c|c|c|c|}
\hline Emitters & $V(\mathrm{~V})$ & $L\left(\mathrm{~cd} \mathrm{~m}^{-2}\right)$ & $\eta_{\text {ex }}(\%)$ & $\eta_{\mathrm{c}}\left(\mathrm{cd} \mathrm{A}^{-1}\right)$ & $\eta_{\mathrm{p}}\left(\operatorname{lm} \mathrm{W}^{-1}\right)$ & $\operatorname{CIE}(x, y)$ & $\mathrm{EL}(\mathrm{nm})$ \\
\hline CADPPI:Ir(ppy) ${ }_{3}$ & 2.6 & 39012 & 23.0 & 80.1 & 87.3 & $0.27,0.62$ & 518 \\
\hline DPIAPPB:Ir(ppy $)_{3}$ & 2.8 & 38765 & 22.1 & 76.2 & 86.5 & $0.27,0.62$ & 524 \\
\hline CADPPI:Ir(MDQ) $)_{2}(\mathrm{acac})$ & 3.0 & 30456 & 21.9 & 26.0 & 26.2 & $0.64,0.35$ & 630 \\
\hline DPIAPPB:Ir(MDQ) $)_{2}(\mathrm{acac})$ & 3.1 & 31068 & 20.6 & 25.1 & 25.3 & $0.64,0.35$ & 636 \\
\hline CBP:Ir(MDQ $)_{2}(\mathrm{acac})$ & 4.0 & 30568 & 10.8 & 22.0 & 22.4 & $0.64,0.40$ & 643 \\
\hline
\end{tabular}

\section{Conclusion}

We have developed new donor-spacer-acceptor compounds, CADPPI and DPIAPPB with bipolar properties and exhibit superior thermal characteristics. The part of the triplet excitons of the blue fluorophores can be utilized to realize reverse intersystem crossing (RISC) from triplet excited states to singlet excited states for blue emission (CADPPI $\mathrm{T}_{2} \stackrel{17.9 \%}{\longrightarrow} \mathrm{S}_{1}$; DPIAPPB $\mathrm{T}_{2} \stackrel{10.1 \%}{\longrightarrow} \mathrm{S}_{1}$ ) and the diffusion volume range of the triplet excitons is reduced significantly. The CADPPI based device (EL $-467 \mathrm{~nm}$ ) shows high efficiencies $\left(\eta_{\mathrm{c}}-9.85 \mathrm{~cd} \mathrm{~A}^{-1} ; \eta_{\mathrm{p}}-10.84 \mathrm{~lm} \mathrm{~W}^{-1} ; \eta_{\mathrm{ex}}-4.78 \%\right)$ at $2.8 \mathrm{~V}$ with CIE $(0.15,0.10)$ compared to DPIAPPB device (EL -472

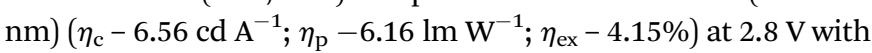
CIE $(0.15,0.12)$. The CADPPI and DPIAPPB are employed as host for green and red phosphorescent devices. The green device based on CADPPI:Ir(ppy) ${ }_{3}$ exhibit maximum $L-39012 \mathrm{~cd} \mathrm{~m}^{-2} ; \eta_{\mathrm{ex}}-$
$23.0 \% ; \eta_{\mathrm{c}}-80.1 \mathrm{~cd} \mathrm{~A}^{-1} ; \eta_{\mathrm{p}}-87.3 \mathrm{~lm} \mathrm{\textrm {W } ^ { - 1 }}$ with $\operatorname{CIE}(0.27,0.62)$ and red device with CADPPI:Ir(MDQ) $)_{2}($ acac) exhibit maximum $L-$ $30456 \mathrm{~cd} \mathrm{~m}^{-2} ; \eta_{\mathrm{ex}}-21.9 \% ; \eta_{\mathrm{c}}-26.0 \mathrm{~cd} \mathrm{~A}^{-1} ; \eta_{\mathrm{p}}-26.2 \mathrm{~lm} \mathrm{~W}^{-1}$ with CIE $(0.64,0.35)$. We have developed a chemical modification strategy to harvest high-performance full-color OLEDs by bipolar luminescent materials having $\mathrm{D}-\pi-\mathrm{A}$ molecular structure.

\section{Conflicts of interest}

The authors declare no conflicts of interest.

\section{Acknowledgements}

One of the author Dr J. Jayabharathi thank Department of Science and Technology (EMR/2014/000094), Defence Research and Development Organization (213/MAT/10-11), Council of 
Scientific and Industrial Research [No. 01/ (2707)/13EMR-II], University Grant Commission (36-21/2008) and Nano Mission (SR/NM/NS-1001/2016) for financial support.

\section{References}

1 (a) C. W. Tang and S. A. VanSlyke, Appl. Phys. Lett., 1987, 51, 913-915; (b) J. H. Burroughes, D. D. C. Bradley, A. R. Brown, R. N. Marks, K. Mackay, R. H. Friend, P. L. Burns and A. B. Holmes, Nature, 1990, 347, 539-541; (c) G. Tan, S. Chen, C. H. Siu, A. Langlois, Y. Qiu, H. Fan, C. L. Harvey, P. D. Ho, Y. H. Liu, L. Lo and W. Y. Wong, J. Mater. Chem. C, 2016, 4, 6016-6026; (d) B. W. D Andrade and S. R. Forrest, Adv. Mater., 2004, 16, 1585-1595; (e) Q. Fu, J. Chen, C. Shi and D. Ma, ACS Appl. Mater. Interfaces, 2012, 4, 6579-6586; ( $f$ ) H. Zhang, H. Wang, J. Li, J. Sun, A. Qin and B. Z. Tang, J. Mater. Chem. C, 2015, 3, 5162-5166; $(g)$ C. Fan, L. Zhu, T. Liu, B. Jiang, D. Ma, J. Qin and C. Yang, Angew. Chem., Int. Ed., 2014, 53, 21472157; (h) P. Y. Gu, Y. Zhao, J. H. Zhang, J. He, C. Wang, Q. F. Xu, J. M. Lu, X. W. Sun and Q. Zhang, J. Org. Chem., 2015, 80, 3030-3035.

2 (a) D. C. Chen, S. J. Su and Y. Cao, J. Mater. Chem. C, 2014, 2, 9565-9578; (b) G. Mallesham, C. Swetha, S. Niveditha, M. E. Mohanty, N. J. Babu, A. Kumar, K. Bhanuprakash and V. J. Rao, J. Mater. Chem. C, 2015, 3, 1208-1224; (c) X. Yang, X. Xu, J. S. Dang, G. Zhou, C. L. Ho and W. Y. Wong, Inorg. Chem., 2016, 55, 1720-1727; (d) D. Sun, X. Zhou, J. Liu, X. Sun, H. Li, Z. Ren, D. Ma, M. R. Bryce and S. Yan, ACS Appl. Mater. Interfaces, 2015, 7, 27989273998; (e) R. Deans, J. Kim, M. R. Machacek and T. M. Swager, J. Am. Chem. Soc., 2000, 122, 8565-8566.

3 (a) J. Lee, H. F. Chen, T. Batagoda, C. Coburn, P. I. Djurovich, M. E. Thompson and S. R. Forrest, Nat. Mater., 2016, 15, 9298; (b) M. Zhu, J. Zou, S. Hu, C. Li, C. Yang, H. Wu, J. Qin and Y. Cao, J. Mater. Chem., 2012, 22, 361-366; (c) C. Y. Kuei, W. L. Tsai, B. Tong, M. Jiao, W. K. Lee, Y. Chi, C. C. Wu, S. H. Liu, G. H. Lee and P. T. Chou, Adv. Mater., 2016, 28, 2795-2800; (d) C. Fan and C. Yang, Chem. Soc. Rev., 2014, 43, 6439-6469; (e) K. H. Kim, J. L. Liao, S. W. Lee, B. Sim, C. K. Moon, G. H. Lee, H. J. Kim, Y. Chi and J. J. Kim, $A d v$. Mater., 2016, 28, 2526-2532.

4 (a) H. Uoyama, K. Goushi, K. Shizu, H. Nomura and C. Adachi, Nature, 2012, 492, 234-238; (b) S. Y. Lee, T. Yasuda, Y. S. Yang, Q. Zhang and C. Adachi, Angew. Chem., Int. Ed., 2014, 53, 6402-6406; (c) D. Zhang, L. Duan, C. Li, Y. Li, H. Li, D. Zhang and Y. Qiu, Adv. Mater., 2014, 26, 5050-5055; (d) J. Luo, S. Gong, Y. Gu, T. Chen, Y. Li, C. Zhong, G. Xie and C. Yang, J. Mater. Chem. C, 2016, 4, 2442-2446; (e) S. Wu, M. Aonuma, Q. Zhang, S. Huang, T. Nakagawa, K. Kuwabara and C. Adachi, J. Mater. Chem. C, 2014, 2, 421-424.

5 (a) L. S. Cui, J. U. Kim, H. Nomura, H. Nakanotani and C. Adachi, Angew. Chem., 2016, 55, 6864-6868; (b) K. Udagawa, H. Sasabe, F. Igarashi and J. Kido, Adv. Opt. Mater., 2016, 4, 86-90; (c) W. Li, J. Li, D. Liu and Q. Jin, ACS Appl. Mater. Interfaces, 2016, 8, 22382-22391; (d)
M. M. Xue, C. C. Huang, Y. Yuan, L. S. Cui, Y. X. Li, B. Wang, Z. Q. Jiang, M. K. Fung and L. S. Liao, ACS Appl. Mater. Interfaces, 2016, 8, 20230-20236.

6 (a) T. A. Lin, T. Chatterjee, W. L. Tsai, W. K. Lee, J. Wu, K. C. Pan, C. L. Yi, C. L. Chung, K. T. Wong and C. C. Wu, Adv. Mater., 2016, 28, 6976-6983; (b) D. R. Lee, M. S. Kim, K. Jeon, S. H. Hwang, C. W. Lee and J. Y. Lee, Adv. Mater., 2015, 27, 5861-5867; (c) P. Rajamalli, N. Senthilkumar, P. Gandeepan, P. Huang, Y. M. J. Huang, C. Z. R. Wu, C. Y. Yang, M. J. Chiu, L. K. Chu, H. W. Lin and C. H. Cheng, J. Am. Chem. Soc., 2016, 138, 628-634; (d) J. S. Kang, T. R. Hong, H. J. Kim, Y. H. Son, R. Lampande, B. Y. Kang, C. Lee, J. K. Bin, B. S. Lee, J. H. Yang, J. W. Kim, S. Park, M. J. Cho, J. H. Kwon and D. H. Choi, J. Mater. Chem. C, 2016, 4, 4512-4520.

7 Y. Sun, N. C. Giebink, H. Kanno, B. Ma, M. E. Thompson and S. R. Forrest, Nature, 2006, 440, 908-912.

8 (a) S. Chen, G. Tan, W. Y. Wong and H. S. Kwok, Adv. Funct. Mater., 2011, 21, 3785-3793; (b) G. M. Farinola and R. Ragni, Chem. Soc. Rev., 2011, 40, 3467-3482; (c) H. Sasabe, J. I. Takamatsu, T. Motoyama, S. Watanabe, G. Wagenblast, N. Langer, O. Molt, E. Fuchs, C. Lennartz and J. Kido, Adv. Mater., 2010, 22, 5003-5007; (d) R. J. Wang, D. Liu, T. H. Ren, C. Zhang, H. M. Yin, G. Y. Liu and J. Y. Li, Adv. Mater., 2011, 23, 2823-2827; (e) M. C. Gather and A. K. K. Meerholz, Adv. Mater., 2011, 23, 233-248; (f) C. Han, Z. Zhang, H. Xu, J. Li, G. Xie, R. Chen, Y. Zhao and W. Huang, Angew. Chem., Int. Ed., 2012, 51, 10104-10108; (g) G. Zhou, C. L. Ho, W. Y. Wong, Q. Wang, D. Ma, L. Wang, Z. Lin, T. B. Marder and A. Beeby, Adv. Funct. Mater., 2008, 18, 499-511.

9 (a) R. Misra, T. Jadhav, B. Dhokale and S. M. Mobin, Chem. Commun., 2014, 50, 9076-9078; (b) J. E. Kwon, S. Park and S. Y. Park, J. Am. Chem. Soc., 2013, 135, 11239-11246.

10 (a) S. J. Su, H. Sasabe, Y. J. Pu, K. Nakayama and J. Kido, Adv. Mater., 2010, 22, 3311-3316; (b) H. Sasane, H. Nakanishi, Y. Watanabe, S. Yano, M. Hirasawa, Y. J. Pu and J. Kido, Adv. Funct. Mater., 2013, 23, 5550-5555; (c) H. Ye, D. Chen, M. S. Liu, J. Su, Y. F. Wang, C. Lo, A. Lien and J. Kido, Adv. Funct. Mater., 2014, 24, 3268-3275.

11 (a) A. C. Morteani, A. S. Dhoot, J. S. Kim, C. Silva, N. C. Greenham, C. Murphy, E. Moons, S. Cina, J. H. Burroughes and R. H. Friend, Adv. Mater., 2003, 15, 1708-1712; (b) T. Matsushima, Appl. Phys. Lett., 2006, 89, 253506-253513; (c) A. K. Pandey and J. M. Nunzi, Adv. Mater., 2007, 19, 3613-3617.

12 C. L. Li, J. Wei, J. Han, Z. Li, X. Song, Z. Zhang, J. Zhang and Y. Wang, J. Mater. Chem. C, 2016, 4, 10120-10129.

13 (a) M. Chen, Y. Yuan, J. Zheng, W. C. Chen, L. J. Shi, Z. L. Zhu, F. Lu, Q. X. Tong, Q. Yang, J. Ye, M. Y. Chan and C. S. Lee, Adv. Opt. Mater., 2015, 3, 1215-1219; (b) Y. Qian, Q. Wei, G. D. Pozo, M. M. Mroz, L. Luer, S. Casado, J. C. Gonzalez, Q. Zhang, L. Xie, R. Xia and W. H. Huang, Adv. Mater., 2014, 26, 2937-2942; (c) D. He, Y. Yuan, B. Liu, D. Y. Huang, C. Y. Luo, F. Lu, Q. X. Tong and C. S. Lee, Dyes Pigm., 2017, 136, 347-353. 
14 W. J. Li, Y. Y. Pan, R. Xiao, Q. M. Peng, S. T. Zhang, D. G. Ma, F. Li, F. Z. Shen, Y. H. Wang, B. Yang and Y. G. Ma, Adv. Funct. Mater., 2014, 24, 1609-1614.

15 S. T. Zhang, W. J. Li, L. Yao, Y. Y. Pan, B. Yang and Y. G. Ma, Chem. Commun., 2013, 49, 11302-11304.

16 L. Yao, S. T. Zhang, R. Wang, W. J. Li, F. Z. Shen, B. Yang and Y. G. Ma, Angew. Chem., Int. Ed., 2014, 53, 2119-2123.

17 Y. Y. Pan, W. J. Li, S. T. Zhang, L. Yao, C. Gu, H. Xu, B. Yang and Y. G. Ma, Adv. Opt. Mater., 2014, 2, 510-515.

18 W. J. Li, Y. Y. Pan, L. Yao, H. C. Liu, S. T. Zhang, C. Wang, F. Z. Shen, B. Yang and Y. G. A Ma, Adv. Opt. Mater., 2014, 2, 892-901.

19 D. Chaudhuri, E. Sigmund, A. Meyer, L. Rcck, P. Klemm, S. Lautenschlager, A. Schmid, S. R. Yost, T. Van, S. Bange, S. Hcger and J. M. Lupton, Angew. Chem., 2013, 52, 1344913452 .

20 J. R. Sheats, H. Antoniadis, M. Hueschen, W. Leonard, J. Miller, R. Moon and D. Roitman, Science, 1996, 273, 884888.

21 T. Forster, Discuss. Faraday Soc., 1959, 27, 7-17.

22 S. Zhang, L. Yao, Q. Peng, W. Li, Y. Pan, R. Xiao, Y. Gao, C. Gu, Z. Wang, P. Lu, F. Li, S. Su, B. Yang and Y. Ma, Adv. Funct. Mater., 2015, 25, 1755-1762.

23 M. A. Baldo, S. Lamansky, P. E. Burrows, M. E. Thompson and S. R. Forrest, Appl. Phys. Lett., 1999, 60, 14422.

24 (a) H. Huang, Y. Wang, S. Zhuang, X. Yang, L. Wang and C. Yang, J. Phys. Chem. C, 2012, 116, 19458-19466; (b) H. Huang, Y. Wang, B. Wang, S. Zhuang, B. Pan, X. Yang, L. Wang and C. Yang, J. Mater. Chem. C, 2013, 1, 58995908; (c) D. Liu, M. Du, D. Chen, K. Ye, Z. Zhang, Y. Liu and Y. Wang, J. Mater. Chem. C, 2015, 3, 4394-4401.

25 K. Wang, S. Wang, J. Wei, S. Chen, D. Liu, Y. Liu and Y. Wang, J. Mater. Chem. C, 2014, 2, 6817-6826.

26 (a) B. Wang, X. Lv, J. Tan, Q. Zhang, Z. Huang, W. Yi and L. Wang, J. Mater. Chem. C, 2016, 4, 8473-8482; (b) X. Ouyang, X. L. Li, L. Ai, D. Mi, Z. Ge and S. J. Su, ACS Appl. Mater. Interfaces, 2015, 7, 7869-7877.

27 M. J. Frisch, G. W. Trucks, H. B. Schlegel, G. E. Scuseria, M. A. Robb, J. R. Cheeseman, J. A. Montgomery, T. Vreven, K. N. Kudin, J. C. Burant, J. M. Millam, S. S. Iyengar, J. Tomasi, V. Barone, B. Mennucci, M. Cossi, G. Scalmani, N. Rega, G. A. Petersson, H. Nakatsuji, M. Hada, M. Ehara, K. Toyota, R. Fukuda, J. Hasegawa, M. Ishida, T. Nakajima, Y. Honda, O. Kitao, H. Nakai, M. Klene, X. Li, J. E. Knox, H. P. Hratchian, J. B. Cross, V. Bakken, C. Adamo, J. Jaramillo, R. Gomperts, R. E. Stratmann, O. Yazyev, A. J. Austin, R. Cammi, C. J. Pomelli, W. Ochterski, P. Y. Ayala, K. Morokuma, G. A. Voth, P. Salvador, J. J. Dannenberg, V. G. Zakrzewski, S. Dapprich. A. D. Daniels, M. C. Strain, O. Farkas, D. K. Malick, A. D. Rabuck, K. Raghavachari, J. B. Foresman, J. V. Ortiz, A. Cui, G. Baboul, S. Clifford, J. Cioslowski, B. B. Stefanov, G. Liu, A. Liashenko, P. Piskorz, I. Komaromi, R. L. Martin, D. J. Fox, T. Keith, M. A. Al-Laham, C. Y. Peng, A. Nanayakkara, M. Challacombe, P. M. W. Gill, B. Johnson, W. Chen, M. W. Wong, C. Gonzalez and
J. A. Pople, Gaussian 03 (Revision E.01), Gaussian, Inc., Wallingford, CT, 2004.

28 Z. Gao, Z. Wang, T. Shan, Y. Liu, F. Shen, Y. Pan, H. Zhang, X. P. He, B. Lu and Y. Ma, Org. Electron., 2014, 15, 2667-2676. 29 (a) Y. Li, Z. Wang, X. Li, G. Xie, D. Chen, Y. F. Wang, C. C. Lo, A. Lien, J. Peng, Y. Cao and S. J. Su, Chem. Mater., 2015, 27, 1100-1109; (b) M. L. Sun, W. S. Zhu, Z. S. Zhang, C. J. L. Ou, H. Xie, Y. Yang, Y. Qian, Y. Zhao and W. Huang, J. Mater. Chem. C, 2015, 3, 94-99.

30 A. Obolda, Q. Peng, C. He, T. Zhang, J. Ren, H. Ma, Z. Shuai and F. Li, Adv. Mater., 2016, 28, 4740-4746.

31 (a) Y. Yu, B. Jiao, Z. Wu, Z. Li, L. Ma, G. Zhou, W. Yu, S. K. So and X. Hou, J. Mater. Chem. C, 2014, 2, 9375-9384; (b) Y. Yu, Z. Wu, Z. Li, B. Jiao, L. Li, L. Ma, D. Wang, G. Zhou and X. Hou, J. Mater. Chem. C, 2013, 1, 8117-8127.

32 R. Kim, S. Lee, K. H. Kim, Y. J. Lee, S. K. Kwon, J. J. Kim and Y. H. Kim, Chem. Commun., 2013, 49, 4664-4666.

33 H. Liu, L. Yao, B. Li, X. Chen, Y. Gao, S. Zhang, W. Li, P. Lu, B. Yang and Y. Ma, Chem. Commun., 2016, 52, 7356.

34 W. Liu, C. J. Zheng, K. Wang, Z. Chen, D. Y. Chen, F. Li, M. X. Ou, Y. P. Dongand and X. H. Zhang, ACS Appl. Mater. Interfaces, 2015, 7, 18930-18936.

35 Y. Tao, Q. Wang, C. Yang, C. Zhong, K. Zhang, J. Qin and D. Ma, Adv. Funct. Mater., 2010, 20, 304-311.

36 C. Fan, Y. H. Chen, Z. Q. Jiang, C. L. Yang, C. Zhong, J. G. Qin and D. G. Ma, J. Mater. Chem., 2010, 20, 3232-3237.

37 Z. Huang, B. Wang, Q. Zhang, S. Xiang, X. Lv, L. Ma, B. Yang, Y. Gao and L. Wang, Dyes Pigm., 2017, 140, 328-336.

38 P. Y. Chou, H. H. Chou and Y. H. Chen, Chem. Commun., 2014, 50, 6869-6871.

39 D. D. Zhang, L. Duan, Y. L. Li, H. Y. Li, Z. Y. Bin, D. Q. Zhang, J. Qiao, G. D. Dong, L. D. Wang and Y. Qiu, Adv. Funct. Mater., 2014, 24, 3551-3561.

40 Y. Li, Y. Liu, W. Bu, D. Lu, Y. Wu and Y. Wang, Chem. Mater., 2000, 12, 2672-2675.

41 (a) C. C. Lai, M. J. Huang, H. H. Chou, C. Y. Liao, P. Rajamalli and C. H. Cheng, Adv. Funct. Mater., 2015, 25, 5548-5556; (b) C. Wang, J. Zhang, G. Long, N. Aratani, H. Yamada, Y. Zhao and Q. Zhang, Angew. Chem., Int. Ed., 2015, 54, 6292-6296; (c) Y. Lin, Q. He, F. Zhao, L. Huo, J. Mai, X. Lu, C. J. Su, T. Li, J. Wang, J. Zhu, Y. Sun, C. Wang and X. A. Zhan, J. Am. Chem. Soc., 2016, 138, 2973-2976.

42 C. Quinton, A. V. Rizzo, C. Dumas Verdes, F. Miomandre, G. Clavier and P. Audebert, RSC Adv., 2014, 4, 34332-34342. 43 Y. Yuan, D. Li, X. Zhang, X. Zhao, Y. Liu, J. Zhang and Y. Wang, New J. Chem., 2011, 35, 1534-1540.

44 (a) W. Z. Yuan, S. M. Chen, J. W. Lam, C. M. Deng, P. Lu, H. M. H. Sung, I. D. Williams, H. S. Kwok, Y. M. Zhang and B. Z. Tang, Chem. Commun., 2011, 47, 11216-11218; (b) X. J. Xu, S. Y. Chen, G. Yu, C. A. Di, H. You, D. G. Ma and Y. Q. Liu, Adv. Mater., 2007, 19, 1281-1285.

45 C. H. Chien, C. K. Chen, F. M. Hsu, C. F. Shu, P. T. Chou and C. H. Lai, Adv. Funct. Mater., 2009, 19, 2834-2843.

46 W. C. Chen, Y. Yuan, G. F. Wu, H. X. Wei, J. Ye, M. Chen, F. Lu, Q. X. Tong, F. L. Wo and C. S. Lee, Org. Electron., 2015, 17, 159-166.

47 R. L. Martin, J. Chem. Phys., 2003, 118, 4775-4777. 
48 S. Tretiak and S. Mukamel, Chem. Rev., 2002, 102, 31713212.

49 S. Zhuang, R. Shangguan, H. Huang, G. Tua, L. Wang and X. Zhu, Dyes Pigm., 2014, 101, 93-102.

50 Z. Ma, E. Wang, M. E. Jarvid, P. Henriksson, O. Inganas, F. Zhang and M. R. Andersson, J. Mater. Chem., 2012, 22, 2306-2314.

51 X. Du, G. Li, J. Zhao, S. Tao, C. Zheng, H. Lin, Q. Tong and X. Zhang, Adv. Opt. Mater., 2017, 5, 1700498-1700508.

52 Z. R. Grabowski, K. Rotkiewicz and W. Rettig, Chem. Rev., 2003, 103, 3899-4032.

53 C. J. Kuo, T. Y. Li, C. C. Lien, C. H. Liu, F. I. Wu and M. J. Huang, J. Mater. Chem., 2009, 19, 1865-1871.

54 V. Bulovic, A. Shoustikov, M. A. Baldo, E. Bose, V. G. Kozlov, M. E. Thomoson and S. R. Forrest, Chem. Phys. Lett., 1998, 287, 455-460.

55 C. Liu, Q. Fu, Y. Zou, C. Yang, D. Ma and J. Qin, Chem. Mater., 2014, 26, 3074-3083.

56 E. Lippert, W. Liider and H. Boos, in Advances in molecular spectroscopy, ed. A. Mangini, Pergamon Press, Oxford, 1962, p. 443.

57 Z. Wang, Y. Feng, S. Zhang, Y. Gao, Z. Gao, Y. Chen, X. Zhang, P. Lu, B. Yang, P. Chen and Y. M. S. Liu, Phys. Chem. Chem. Phys., 2014, 16, 20772-20779.

58 L. Duan, J. Qiao, Y. D. Sun and Y. Qiu, Adv. Mater., 2011, 23, 1137-1144.

59 C. Li, S. Wang, W. Chen, J. Wei, G. Yang, K. Ye, Y. Li and Y. Wang, Chem. Commun., 2015, 51, 10632-10635.

60 (a) Y. P. Li, F. Li, H. Y. Zhang, Z. Q. Xie, W. J. Xie, H. Xu, B. Li, F. Z. Shen, L. Ye, M. Hanif, D. G. Ma and Y. G. Ma, Chem. Commun., 2007, 3, 231-233; (b) Y. P. Li, F. Z. Shen, H. Wang, F. He, Z. Q. Xie, H. Y. Zhang, Z. M. Wang, L. L. Liu, F. Li, M. Hanif, L. Ye and Y. G. Ma, Chem. Mater., 2008, 20, 7312-7318.

61 S. P. Jagtap, S. Mukhopadhyay, V. Coropceanu, G. L. Brizius, J. Bré das and D. M. Collard, J. Am. Chem. Soc., 2012, 134, 7176-7185.

62 H. Zhuang, Q. Zhou, Q. Zhang, H. Li, N. Li, Q. Xua and J. Lu, J. Mater. Chem., 2015, 3, 416-422.

63 Y. P. Yurenko, J. Novotný, V. Sklenářabc and R. Marek, Phys. Chem. Chem. Phys., 2014, 16, 15241-15248.

64 (a) M. S. Tsai, Y. C. Hsu, J. T. Lin, H. C. Chen and C. P. Hsu, J. Phys. Chem. C, 2007, 111, 18785-18793; (b) Y. N. Yan, W. L. Pan and H. C. Song, Dyes Pigm., 2010, 86, 249-258; (c) T. W. Kim, S. H. Oh, H. Choi, G. Wang, H. Hwang, D. Y. Kim and T. Lee, Appl. Phys. Lett., 2008, 92, 253308253313.

65 W. C. Chen, Y. Yuan, G. F Wu, H. X. Wei, L. Tang, Q. X. Tong, F. L. Wong and C. S. Lee, Adv. Opt. Mater., 2014, 2, 626-631. 66 C. Lambert, T. Scherpf, H. Ceymann, A. Schmiedel and M. Holzapfel, J. Am. Chem. Soc., 2015, 137, 3547-3557.
67 J. Jayabharathi, R. Ramya, V. Thanikachalam, P. Jeeva and E. Sarojpurani, RSC Adv., 2019, 9, 2948-2966.

68 Q. Zhang, J. Li, K. Shizu, S. Huang, S. Hirata, H. Miyazaki and C. Adachi, J. Am. Chem. Soc., 2012, 134, 14706-14709.

69 M. R. Zhu and C. L. Yang, Chem. Soc. Rev., 2013, 42, 49634976.

70 H. H. Chou, Y. H. Chen, H. P. Hsu, W. H. Chang, Y. H. Chen and C. H. Cheng, Adv. Mater., 2012, 24, 5867-5871.

71 Y. Liu, L. S. Cui, M. F. Xu, X. B. Shi, D. Y. Zhou, Z. K. Wang, Z. Q. Jiang and L. S. Liao, J. Mater. Chem. C, 2014, 2, 24882495.

72 Y. H. Lou, M. F. Xu, L. Zhang, Z. K. Wang, S. Naka, H. Okada and L. S. Liao, Org. Electron., 2013, 14, 2698-2704.

73 Z. Wang, Y. Lou, S. Naka and H. Okada, Appl. Phys. Lett., 2011, 98, 063302-063303.

74 J. Liu, Z. Zeng, X. Cao, G. Lu, L. H. Wang, Q. L. Fan, W. Huang and H. Zhang, Small, 2012, 8, 3517-3522.

75 T. Lu and F. Chen, J. Comput. Chem., 2012, 33, 580-592.

76 (a) S. T. T. Tsutsui and Y. Taga, J. Appl. Phys., 1999, 86, 24072411; (b) S. H. Cho, J. R. Oh, H. K. Park, H. K. Kim, Y. H Lee, J. G. Lee and Y. R. Do, Opt. Express, 2010, 18, 1099-1104.

77 A. O. Eseola, O. Adepitan, H. Gorls and W. Plass, New J. Chem., 2012, 36, 891-902.

78 (a) Y. Tan, Z. Zhao, L. Shang, Y. Liu, C. Wei, J. Li, H. Wei, Z. Liu, Z. Bian and C. A Huanga, J. Mater. Chem. C, 2017, 5, 11901-11909; (b) W. Li, L. Yao, H. Liu, Z. Wang, S. Zhang, R. Xiao, H. Zhang, P. Lu, B. Yang and Y. Ma, J. Mater. Chem. C, 2014, 2, 4733-4736.

79 H. Liu, Q. Bai, L. Yao, H. Zhang, H. Xu, S. Zhang, W. Li, Y. Gao, J. Li, P. Lu, H. Wang, B. Yang and Y. Ma, Chem. Sci., 2015, 6, 3797-3804.

80 Z. Wang, Y. Feng, H. Li, Z. Gao, X. Zhang, P. Lu, P. Chen, Y. Ma and S. Liu, Phys. Chem. Chem. Phys., 2014, 16, 10837-10843.

81 S. Tang, W. J. Li, F. J. Shen, D. D. Liu, B. Yang and Y. G. Ma, J. Mater. Chem., 2012, 22, 4401-4408.

82 Y. Zhang, T. W. Ng, F. Lu, Q. X. Tong, S. L. Lai, M. Y. Chan, H. L. Kwong and C. S. A. Lee, Dyes Pigm., 2013, 98, 190-194.

83 X. L. Li, X. Ouyang, D. Chen, X. Cai, M. Liu, Z. Ge, Y. Cao and S. J. Su, Nanotechnology, 2016, 27, 124001-124011.

84 M. T. Lee, H. H. Chen, C. H. Liao, C. H. Tsai and C. H. Chen, Appl. Phys. Lett., 2004, 85, 3301-3303.

85 Y. Zhang, S. L. Lai, Q. X. Tong, M. F. Lo, T. W. Ng, M. Y. Chan, Z. C. Wen, J. He, K. Jeff, X. L. Tang, W. M. Liu, C. C. Ko, P. F. Wang and C. S. Lee, Chem. Mater., 2012, 24, 61-70.

86 F. I. Wu, P. I. Shih, M. C. Yuan, A. K. Dixit, C. F. Shu, Z. M. Chung and E. W. G. Diau, J. Mater. Chem., 2005, 15, 4753-4760.

87 Y. L. Liao, C. Y. Lin, K. T. Wong, T. H. Hou and W. Y. Hung, Org. Lett., 2007, 9, 4511-4514.

88 J. Yang, Q. Guo, J. Wang, Z. Ren, J. Chen, Q. Peng, D. Ma and Z. Li, Adv. Opt. Mater., 2018, 6, 1800342-1800348. 